Cahiers $d u$ MONDE RUSSE

\section{Cahiers du monde russe}

Russie - Empire russe - Union soviétique et États indépendants

$50 / 1 \mid 2009$

Écrits personnels. Russie XVIII ${ }^{\mathrm{e}} \mathrm{XX} \mathrm{X}^{\mathrm{e}}$ siècles

\title{
Lemnos, l'île aux Cosaques
}

BRUNO BAGNI

\section{OpenEdition \\ Journals}

Édition électronique

URL : https://journals.openedition.org/monderusse/9162

DOI : 10.4000/monderusse.9162

ISSN : $1777-5388$

Éditeur

Éditions de l'EHESS

Édition imprimée

Date de publication : 31 mars 2009

Pagination : $187-230$

ISBN : 978-2-7132-2259-7

ISSN : $1252-6576$

\section{Référence électronique}

BRUNO BAGNI, «Lemnos, I'île aux Cosaques », Cahiers du monde russe [En ligne], 50/1 | 2009, mis en ligne le 01 janvier 2009, consulté le 02 septembre 2022. URL : http://journals.openedition.org/ monderusse/9162 ; DOI : https://doi.org/10.4000/monderusse.9162 


\section{BRUNO BAGNI}

\section{LEMNOS, L'ÎLE AUX COSAQUES}

Qui connaît Lemnos ? Isolée au nord de la mer Égée, à mi-chemin entre Lesbos et Thasos, à une centaine de kilomètres de la côte de Thrace, cette île grecque fait rarement parler d'elle. Son chef-lieu, Moudros, n'est qu'un gros village de 1700 habitants. Ignorée par le flot de touristes qui font la fortune des autres îles grecques, elle n'est guère prospère. Base navale des Alliés lors de la désastreuse expédition des Dardanelles en 1915, c'est là que fut signé, en octobre 1918, l'armistice entre les Turcs et l'Entente. Tout le monde semble avoir oublié qu'elle fut, pendant les années 1920-1921, un refuge pour des milliers de Cosaques fuyant la Russie à la fin de la guerre civile, lors de la grande offensive de l'Armée rouge dans le sud du pays. Pourquoi ont-ils échoué là ? Comment ces milliers de réfugiés ont-ils pu survivre sur une île aride et dénuée de ressources? Dans quelles circonstances l'ont-ils quittée ? L'histoire du transit des Cosaques de l'armée Wrangel sur l'île de Lemnos a, jusqu'à présent, été essentiellement traitée à partir de témoignages et d'archives russes lesquels ont dépeint de façon plutôt négative l'action des autorités françaises qui organisèrent et supervisèrent l'accueil de ces troupes. Le dépouillement d'archives françaises, principalement militaires, fournit ici un autre éclairage sur cet épisode de la dispersion des Cosaques et se révèle assez sévère sur le comportement des Russes, confirmant la gravité des contentieux, voire des malentendus entre Russes et Français.

Automne 1920 : l'armée blanche du général Wrangel, réfugiée dans la péninsule de Crimée, résiste aux assauts de l'Armée rouge depuis le mois d'avril. Le 10 novembre, le front est percé et les Rouges se dirigent vers Sevastopol'. Plus rien ne peut désormais les arrêter et Wrangel donne l'ordre d'évacuer la Crimée. Quelque 150000 réfugiés quittent alors la Russie, dont des dizaines de milliers de Cosaques. Lorsque la flotte Wrangel quitte les côtes de Crimée, il y a à bord 19500 Cosaques du Kuban', 26500 Cosaques du Don, quelques centaines de Cosaques du Terek et d'Astrahan', 2000 Kalmouks' $^{1}$ enfin.

1. SHMV (Service historique de la Marine à Vincennes), 1BB4 17, lettre 125 du vice-amiral de Bon au ministre de la Marine, 12 décembre 1920. 
L'évacuation est supervisée par la Marine française. Seul des forces alliées, le Gouvernement français a reconnu celui du général Wrangel et lui a apporté une aide logistique, via la base de la Marine française située à proximité de la Russie : depuis l'armistice, les armées de l'Entente occupent Constantinople et patrouillent régulièrement en mer Noire. C'est dans une capitale vaincue et occupée qu'arrivent en ce mois de novembre 1920 les réfugiés russes. Dès lors, il est évident que pour le Gouvernement français l'armée russe a cessé d'exister et qu'il s'agit de considérer les soldats comme de simples réfugiés. Mais les autorités militaires et navales françaises ne voient pas les choses ainsi : selon elles, une dispersion de l'armée russe sans aucune perspective d'emploi risquerait de rendre cauchemardesque la situation à Constantinople. Elles se prononcent donc pour le maintien de la discipline militaire. Les troupes doivent être laissées sous les ordres des officiers russes, sous peine de les voir se transformer en mercenaires, voire en « grandes compagnies ». Elles préconisent aussi une dispersion progressive des réfugiés dans les pays qui voudront bien les accueillir. Bien qu'à contrecœur, le Gouvernement se rallie à ces arguments.

Fin tacticien, Wrangel s'engouffre par cette porte laissée entrouverte. Il profite de l'autorité que lui laissent les Français pour s'opposer par tous les moyens à la dispersion de son armée. Propagande, pression psychologique, menaces, tout est bon pour garder un noyau irréductible d'armée blanche : Wrangel caresse toujours le rêve de reprendre la lutte contre les Soviets ou de s'emparer du pouvoir si celui des Bolcheviks venait à s'effondrer de lui-même.

Ainsi, le séjour des Cosaques à Lemnos, qui va durer un an, sera marqué par un bras de fer permanent entre Wrangel et son état-major et les autorités françaises. Celles-ci désirent se débarrasser au plus vite de réfugiés dont l'entretien se révèle fort coûteux pour le budget de la France.

Voici l'histoire de ce bras de fer, dont l'issue va déterminer le sort de milliers d'hommes.

\section{La création du camp de Lemnos}

\section{Le casse-tête de la gestion des réfugiés}

En une semaine, 130 navires arrivent à Constantinople avec près de 150000 réfugiés à bord, souvent dans un entassement ahurissant et dans un état sanitaire catastrophique. Les autorités françaises de Constantinople sont dépassées : que faire de cette masse énorme de réfugiés ? Les laisser débarquer à Constantinople est inconcevable : la ville est déjà surpeuplée de réfugiés, la Turquie est en pleine guerre civile, Mustafa Kemal contrôle pratiquement toute l'Anatolie.

Il faut donc éloigner au plus vite les Russes de cette poudrière. La flotte de guerre est envoyée à Bizerte. Pour les troupes et les réfugiés civils, les autorités françaises lancent un appel aux États balkaniques, lesquels au lendemain de la 
guerre n'ont pas de grande capacité d'accueil: la Roumanie n'accepte que 2000 réfugiés, la Grèce 1700 , la Bulgarie 3800 ; seule la Serbie, fidèlement russophile, ouvre grand ses portes et en recueille 22300 . Tout cela, en comptant la Tunisie, ne fait que 34000 personnes au 1er janvier 1921. Restent donc plus de 100000 réfugiés à loger et nourrir. Hantés par les vieux spectres de la «Question d'Orient », Britanniques et Français veulent impérativement éloigner les soldats de Constantinople. Mais vers quels pays les diriger?

\section{Le choix de Lemnos}

Le 14 novembre 1920, jour de l'arrivée du premier navire de réfugiés dans le Bosphore, le Gouvernement britannique fait savoir qu'il «ne veut leur donner aucune assistance, ni les recevoir à Lemnos, à Chypre ou en Égypte ». En effet, Lloyd George ne pardonne pas à Wrangel d'avoir repoussé ses offres de médiation pour faire la paix avec les Soviets. Pour être bien clair, le Foreign Office ajoute que «toute responsabilité incombe[rait] uniquement au gouvernement français puisqu'il a[vait] reconnu le gouvernement de Wrangel ». Commentaire du général Nayral de Bourgon : "C'était net et cordial... comme une gifle $»^{2}$. Defrance, hautcommissaire français à Constantinople, décide aussitôt d'installer un grand camp de baraquements et de tentes sur la presqu'île de Gallipoli. En attendant, décision est prise de ne laisser débarquer aucun réfugié, à l'exception des blessés, malades, femmes et enfants ${ }^{3}$.

La brutalité du Gouvernement de Londres heurte profondément des militaires britanniques qui furent longtemps le principal soutien des Blancs. Dès le 15 novembre, le haut-commissaire britannique de Robeck fait savoir à son homologue français que ses instructions « sont indignes du gouvernement britannique », « qu'il n'y avait plus de question de neutralité ni [...] de politique mais uniquement [...] d'humanité ». Il promet aux Français toute l'aide qu'il pourra donner «sans enfreindre trop ouvertement ses instructions » et ajoute que le général Harrington qui commande les troupes britanniques à Constantinople - est « dans les mêmes dispositions » et prêt à « céder tout le matériel disponible »4.

Pendant ce temps, les navires de réfugiés continuent d'arriver au port. La situation sanitaire est explosive, les risques de révolte sur les bateaux sont réels ; on signale même des cas d'asphyxie liée à l'entassement ${ }^{5}$. Le 17 novembre, Defrance avertit les Britanniques que, face à cette crise, il est prêt à prendre la responsabilité de faire débarquer les réfugiés à Lemnos, avec ou sans autorisation de Londres.

2. Pierre-Émile Nayral de Bourgon, 10 ans de souvenirs 1914-1924, Nîmes : imprimerie Chastanier frères et Almeras, 1932.

3. SHMV, 1BB7 159, télégramme vert 1556-1557-1558 de Defrance aux Affaires étrangères, 14 novembre 1920 .

4. Ibid., télégramme vert 1560-1561 de Defrance aux Affaires étrangères, 15 novembre 1920.

5. Ibid., télégramme vert 1582 de Defrance aux Affaires étrangères, 18 novembre 1920. 
Dans les heures qui suivent, le Foreign Office fait enfin parvenir son accord, à condition que la France prenne à sa charge «toutes les dépenses et toutes les responsabilités »6. Tous les Cosaques, soit 35000 à 40000 iront à Lemnos, l'armée régulière sera cantonnée à Gallipoli. Les civils, jugés moins dangereux, seront répartis dans plusieurs camps autour de Constantinople.

Pourquoi Lemnos ? Ottomane jusqu'en 1914 mais peuplée de Grecs, l'île a été attribuée à la Grèce après la guerre tout en restant encore sous occupation britannique. Base arrière de la bataille des Dardanelles, les Britanniques ont installé un camp de réfugiés au village de Moudros pendant la guerre civile russe. En 1920, il reste de tout cela 1600 tentes et des baraquements permettant d'abriter immédiatement 10000 personnes ${ }^{7}$. L'île est aride, mais une canalisation acheminant l'eau depuis le centre de l'île en fournit cinquante mille litres par jour ; le complément est assuré par une station de dessalement. Au total quinze à dix-sept litres par jour et par personne sont disponibles pour 10000 réfugiés. D'autre part, la Croix-Rouge russe y dispose d'un hôpital tout équipé de 200 lits, ainsi que de deux appareils de désinfection ${ }^{8}$.

Dès le lendemain du feu vert britannique, les premières mesures sont prises. Seuls seront envoyés des militaires en unités constituées avec leurs officiers, ainsi que le personnel russe de santé et d'intendance nécessaire. Le ravitaillement sera assuré par l'armée française, la Marine se chargeant de l'acheminement. Le commandant français du camp disposera de quatre officiers, d'un représentant de l'intendance et d'une compagnie de tirailleurs sénégalais. Le commandant russe du camp sera sous l'autorité absolue du commandant français. La Marine met à disposition un aviso stationnaire pour aider au maintien de l'ordre, aux opérations maritimes, au ravitaillement et à l'installation des camps ${ }^{9}$. Le général Broussaud est nommé chef du camp. C'est un russophone qui connaît bien le monde slave : il a participé à l'évacuation et à la reconstitution de l'armée serbe pendant la Grande Guerre. Après la reconnaissance du gouvernement Wrangel par la France, il a été nommé chef de la mission militaire française auprès de Wrangel; il a ainsi été évacué de Crimée en même temps que les Cosaques. Il arrive à Lemnos le 21 novembre $1920^{10}$ et reçoit comme première consigne d'étudier les possibilités d'accueillir au plus vite 20000 Cosaques supplémentaires ${ }^{11}$. Les autorités françaises comptent à terme arriver à héberger 60000 réfugiés à Lemnos.

6. Ibid., télégramme vert 1579 de Defrance aux Affaires étrangères, 17 novembre 1920.

7. SHMT (Service historique de la Marine à Toulon), 56 C 59-60, note de service 2399/3 du chef d'état-major du Corps d'occupation français de Constantinople (COC), 18 novembre 1920 .

8. Ibid., $57 \mathrm{C} 11$, rapport $\mathrm{n}^{\circ} 2$ de la mission d'installation des réfugiés russes à Lemnos, 19 novembre 1920.

9. Ibid., C 12-13, instructions 203 du capitaine de vaisseau Vandier au stationnaire de Moudros, 3 décembre 1920 .

10. Jean Bernachot, Les armées françaises en Orient après l'armistice de 1918, P. : Imprimerie nationale, 1972, p. 92.

11. SHMT, 56 C 59-60, note de service 2399/3 du chef d'EM du COC, 18 novembre 1920. 


\section{La création des camps de Tchataldja}

Il y a cependant urgence : les réfugiés entassés sur les bateaux en rade de Moda sont exposés à des risques importants d'épidémie. Il est décidé de créer un autre camp de Cosaques en Thrace, à Hademkeui-Tchataldja, sous l'autorité du chef de bataillon Teisseire. Les hommes du Don iront à Tchataldja, ceux du Kuban’ à Lemnos. Le transport des réfugiés par train commence le 22 novembre ${ }^{12}$. Le 28 , le camp abrite 21000 Cosaques, hommes, femmes et enfants, sous le commandement du général Abramov, 5500 restent encore sur les navires.

Le camp de Tchataldja se compose en fait de trois camps distincts. Celui de Kabadja (4 000 hommes), situé à $35 \mathrm{~km}$ au nord-ouest d'Hadem Keui et celui de Tchilinguir (8000 hommes), à $7 \mathrm{~km}$ au nord-est de la même ville, sont installés dans d'anciennes fermes d'élevage de vers à soie. Celui de Sandjak Tépé (4 000 hommes), à $2 \mathrm{~km}$ au nord, est une ancienne caserne. Selon l'ataman Bogaevskij, les Cosaques vivent «dans des conditions hygiéniques fort précaires, entassés, mal logés, mal nourris et manquant complètement de médicaments $»^{13}$. Paul Robinson décrit le camp de Tchilinguir «où régnait le choléra et où les logements étaient exigus »14. L'écrivain britannique Philip Longworth évoque, sans citer de source précise, des conditions de vie épouvantables :

Les toits des baraquements infestés de punaises [...] laissaient passer l'eau ; le sol était couvert d'immondices. Il n'y avait pas de lit et rien pour se laver. Ceux qui n'eurent pas la chance de trouver une place dans les baraquements durent vivre dans des terriers creusés dans la terre froide. ${ }^{15}$

Il reste difficile de faire la part de l'exagération dans tout cela (les immondices pourraient s'expliquer : selon Paul Robinson, les Cosaques refusaient d'utiliser les latrines). Cela ne remet pas en cause pour autant la précarité des conditions de vie, Tchataldja n'étant qu'un pis aller provisoire avant le regroupement, programmé, de tous les Cosaques à Lemnos.

\section{L'arrivée des Koubanais à Lemnos}

Le 21 novembre, le Vladimir arrive à Lemnos avec 8500 Koubanais :

Cette terre - raconte un témoin, à mesure que nous approchions, nous offrait sa couleur jaunâtre, et son absence absolue de végétation. Sa vue seule était

12. Ibid., note de service 2427/3 du chef d'EM du COC, 20 novembre 1920.

13. SHAT (Service historique de l'armée de terre), 20 N 1154, rapport 725/A du colonel Rougier au général commandant le COC, 3 décembre 1920.

14. Paul Robinson, The White Army in Exile, 1920-1941, Oxford : Oxford University Press, 2002, p. 35 .

15. Philip Longworth, Les Cosaques, P. : Albin Michel 1972. 
parfaitement démoralisante. [...] L'endroit où nous avons débarqué figurait une presqu'île réunie à l'île par un isthme étroit. [...] On voyait un grand bâtiment qui servait à rendre potable l'eau de mer, et, à côté, plusieurs baraques en bois. Un peu plus loin, un immense hangar en bois, aux murs badigeonnés de goudron. [...] Chacun de nous a reçu un morceau de pain et une petite boîte de pâté. C'était la première nourriture que nous recevions depuis quatre jours. Ensuite, on nous a donné une tente pour 10 personnes, et indiqué l'emplacement où nous devions dresser notre camp. Bientôt, une ville de tentes a surgi, et l'île a pris un air moins rébarbatif. Il faisait froid, et nous grelottions sous nos tentes qui, d'origine anglaise, étaient pourtant très bien doublées, et parfaitement imperméables. [...] Vers minuit, tout le monde a été réveillé par un formidable vacarme. Des cris, des craquements de planches qu'on arrache. Bientôt, tout le monde était dehors, et la nuit de lune nous a offert un spectacle étonnant : on démolissait le hangar ! Les Cosaques, qui avaient froid dans leur tente, avaient décidé de prendre le seul bois qui se trouvait sur l'île. [...] Au matin, le hangar, long de 100 mètres au moins, large de dix et haut de cinq, avait complètement disparu. Les Cosaques sont très ingénieux : de ces innombrables bidons vides que les armées modernes laissent derrière elles, ils ont fait des poêles primitifs. ${ }^{16}$

Dans les deux jours qui suivent arrivent le Lazaref (1 200 hommes) et le Don (6 000 hommes) ; mais le débarquement ne peut se faire qu'à raison de 2000 hommes par jour, par des rotations de chalands : en effet, les quais de Moudros ne peuvent accueillir que des bâtiments à très faible tirant d'eau. Arrivé le 29 novembre, le général Fostikov prend le commandement des troupes cosaques de Lemnos.

Lorsque, à la fin du mois, le général de Bourgon, commandant le COC (Corps d'occupation français de Constantinople), vient faire une inspection, il trouve la situation très satisfaisante eu égard aux circonstances critiques ; paradoxalement, il loue l'esprit et la conduite des Cosaques, «bien qu'ils restent passifs et n'aident guère à l'installation et à l'organisation des camps »; il est par contre très critique vis-à-vis des officiers, estimant «nécessaire d'en retirer un certain nombre du milieu des troupes et de les envoyer le plus loin possible ${ }^{17}$. Broussaud trouve lui aussi que les officiers sont en surnombre : « Force nous est bien de constater que les Russes n'ont rien appris, ou rien voulu apprendre à l'école de la défaite, et qu'ils entendent continuer à constituer leurs cadres et la dotation de leurs services sur le même pied exagéré qu'auparavant ${ }^{18}$. Notons, à titre d'exemple qu'un corps d'artillerie compte 95 officiers.

16. Nicolas Svidine, Le secret de Nicolas Svidine, P. : Laffont, 1973, p. 108-110.

17. SHMV, 1BB7 159, télégramme vert 1661-1662 de Defrance aux Affaires étrangères, $1^{\text {er }}$ décembre 1920.

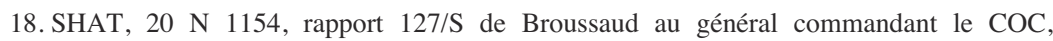
30 novembre 1920 . 


\section{Le transfert des Cosaques du Don à Lemnos}

Dès le 3 décembre, il est décidé que les 5500 Cosaques du Don encore sur les navires en rade de Moda seront débarqués à Lemnos, et non à Tchataldja. C'est ainsi que les premiers hommes du Don arrivent à Moudros ${ }^{19}$. L'harmonie ne régnant guère entre les deux peuples, ils ne sont pas mélangés avec les Koubanais et sont répartis dans trois camps : un de 5000 hommes à proximité immédiate de Moudros, un autre de 5000 places au village de Romano, au nord de Moudros, et le plus important, 10000 hommes, au sud de la ville.

De plus, en raison d'une quarantaine due à une épidémie de choléra au camp de Tchilinguir ${ }^{20}$, les Cosaques de Tchataldja doivent être évacués sur Lemnos. La date

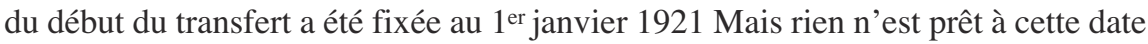
pour les accueillir. Le 31 décembre, le commandant du stationnaire français dresse le tableau suivant :

Le détachement de Moudros-Est [480 Cosaques] avait été envoyé pour préparer les emplacements destinés aux gens évacués de Tchataldja. Mais, quoique le Marietta ait au cours de 3 voyages apporté près de 500 tôles cintrées, rien n'a été fait. Les tôles cintrées encombraient à la date du 29 la jetée [...]. En fait, en prenant 4 hommes pour porter une tôle, à raison de 200 hommes employés, et en supposant que pour faire le kilomètre qui les sépare des emplacements prévus chaque groupe d'homme emploie la journée, les tôles cintrées auraient dû être sur leurs emplacements depuis longtemps [...]. Aucun officier français n'étant en permanence à Moudros-Est, il ne faut pas s'attendre à une grande activité des corvées russes, dont les cadres sont confortablement installés dans les anciens baraquements de la direction du port. ${ }^{21}$

Le début du transfert est donc repoussé courant janvier. Survient alors un autre problème : l'obstruction des autorités russes. Le président du Conseil, Georges Leygues, las de dépenser des fortunes pour l'entretien des réfugiés, a fixé au 1er février la fin de l'aide française ; à partir de cette date, les réfugiés doivent être ravitaillés par une association de secours russe, aux contours très flous. Jouant sur cette ambiguïté, Wrangel, ulcéré de n'avoir pas été consulté, refuse jusqu'à la veille du départ de donner l'ordre de transfert aux Cosaques $^{22}$. L'ordre est finalement donné, mais les Cosaques craignent désormais d'être laissés sans ravitaillement sur une île désertique. L'effervescence est telle que des coups de feu sont échangés entre les troupes françaises et des Cosaques du régiment Kaledin, faisant cinq blessés

19. SHMT, 57 C 10, ordre 1584 du capitaine de vaisseau Vandier, chef d'état-major de l'EMOR (Escadre de Méditerranée orientale), 3 décembre 1920.

20. Ibid., 56 C 59-60, lettre 2848/3 du général Charpy au vice-amiral commandant en chef de l'EMOR, 22 décembre 1920.

21. Ibid., 57 C 27, rapport du lieutenant de vaisseau Tavera, Commandant du Duchaffault, 31 décembre 1920 .

22. ADQO (Archives diplomatiques du Quai d'Orsay), Europe 1918-1940, URSS 259, lettre 5051 de Wrangel au général Charpy, 10 janvier 1921. 
(deux Français et trois Russes) ${ }^{23}$. Plusieurs centaines de réfugiés s'évadent ${ }^{24}$ et se dispersent dans les campagnes dans le but probable de gagner la Grèce; de nombreux cas de vols à main armée, deux meurtres même sont aussi signalés par les autorités ottomanes ${ }^{25}$.

L'agitation finit par retomber, et le premier convoi de 3000 réfugiés part le 13 janvier. Puis tout s'arrête « par suite du retard dans le montage des installations supplémentaires de Moudros et [...] du peu d'enthousiasme du commandement russe pour ce mouvement ${ }^{26}$. Deux autres contingents, au total 6000 hommes, sont transférés les 23 et 24 mars 1921, avec à leur tête le général Abramov, commandant du corps du Don et son état-major. Il n'y en aura plus d'autres. Le camp de Kabadja continuera d'abriter quelques centaines de Cosaques du Don jusqu'au 6 décembre 1921, soit bien après la fermeture des camps de Lemnos.

\section{La vie quotidienne à Lemnos}

\section{Les relations entre les Cosaques et les autorités françaises}

Les difficultés relationnelles entre les autorités françaises et les Russes qui jalonnent toute l'histoire du transit à Lemnos tiennent avant tout au contentieux sur le devenir de l'armée russe : la question du sort de l'armée et de son encadrement s'est posée dès avant l'arrivée du premier bateau à Constantinople. Le 30 novembre 1920, il est décidé en Conseil des ministres de donner à tous les Russes évacués le statut de réfugié civil et une assistance purement humanitaire. Georges Leygues, justifie ainsi cette mesure :

Le maintien d'une armée, qui n'a pas su se battre en Crimée où elle avait une base et des approvisionnements, ne peut présenter au point de vue militaire aucune utilité ; il ne faut pas d'ailleurs compter pour lutter contre les Soviets, l'expérience l'a trop prouvé, sur des forces militaires russes. Ce maintien aurait, par contre, les plus graves inconvénients ; il se heurterait à des difficultés d'ordre international, il serait un véritable péril dans des régions déjà si troublées; enfin il entraînerait des dépenses considérables d'entretien et de solde qu'on ne peut songer à imposer au budget français. ${ }^{27}$

23. SHMV, 1 BB7 159, télégramme vert 70 de Defrance aux Affaires étrangères, 14 janvier 1921.

24. Selon Paul Robinson, il s'agit de deux escadrons, y compris leurs officiers.

25. SHAT, 20 N 1154, lettre G26316 des Affaires étrangères de la Sublime Porte au hautcommissaire français, 31 janvier 1921.

26. SHMT, 57 C 9, rapport mensuel du chef d'état-major de l'EMOR au ministre de la Marine, février 1921 .

27. SHMV, 1BB3/5, télégrammes 2171 à 2175 de Georges Leygues au haut-commissaire français à Constantinople, 9 décembre 1920 . 
Cette position suscite les protestations de Wrangel, pour qui

l'application aux troupes du régime individuel des réfugiés civils affecterait cruellement leur moral et entraînerait irrémédiablement leur décomposition en transformant l'armée en une agglomération de 70000 hommes inaccessibles à toute influence raisonnable..$^{28}$

Cet avis reçoit l'appui des autorités militaires françaises de Constantinople, qui craignent aussi les risques du désœuvrement qu'entraînerait le démantèlement de l'armée. Nayral de Bougon « considère comme très dangereux de leur annoncer dès maintenant qu'on va les transformer en réfugiés civils, et par contre comme nécessaire de continuer à les traiter en soldats $»^{29}$.

L'amiral de Bon évoque quant à lui le risque de les voir se livrer au brigandage ou s'enrôler dans les troupes kémalistes.

Le Gouvernement finit donc par admettre que la dissolution ne pourra se faire qu'en douceur, en trouvant des pays d'accueil pour ces hôtes encombrants. Cela promet d'être très long. En attendant, il faut maintenir la discipline de cette masse, alors que les militaires français sur place sont bien peu nombreux. Nayral de Bourgon en tire les conséquences : «L'armée Wrangel est toute organisée, en bon état de discipline : il y a donc avantage à conserver cette organisation, tout en maintenant [...] la subordination au commandement français $»^{30}$. Ce n'est donc que faute d'alternative que le Gouvernement français consent à conserver ce que Broussaud appelle « la fiction» de cette armée. Elle est laissée sous le commandement de Wrangel car, selon l'amiral de Bon, « l'ascendant que le Général [...] exerce encore sur son armée est une force dont nous devons nous servir pour éviter toute aventure $»^{31}$. Cette ambiguïté pèsera lourd dans les relations entre les Cosaques et les autorités françaises.

Car Wrangel, contrairement à ce qu'il dit aux Français, n'entend nullement disperser son armée, mais la conserver pour reprendre la lutte contre les Soviets. D'abord dissimulée, cette volonté est ensuite ouvertement proclamée, en particulier dans ses discours lors de sa visite de février aux camps de Lemnos. Des circulaires secrètes, envoyées à ses officiers supérieurs, prescrivent de contrecarrer toutes dispositions nuisibles à la conservation de l'armée ${ }^{32}$. Dès lors, ses relations avec les autorités françaises vont très vite se dégrader, et il en va de même avec les commandants russes des camps qu'il a lui-même désignés, en l'occurrence à Lemnos le général Fostikov.

Ces commandants ont un statut singulier. Placés sous l'autorité de Wrangel, ils sont aussi sous celle des commandants français, dont Broussaud à Lemnos. Celui-ci

28. SHMT, 56 C 59-60, lettre de Wrangel au général de Bourgon, 6 décembre 1920.

29. Ibid., lettre 2674/3 du général commandant le COC au haut-commissaire français à Constantinople, 8 décembre 1920.

30. SHAT, 20 N 1155, rapport du général Nayral de Bourgon, 19 novembre 1920.

31. SHMV, 1BB4/17, lettre 125 MS du vice-amiral de Bon au ministre de la Marine, 12 décembre 1920 .

32. SHAT, 20 N 1154, lettre 3523/3 du général Charpy au général Pellé, 9 mars 1921. 
a reçu consigne d'exercer son autorité «avec toute la courtoisie et toute la déférence dues à l'âge et à l'ancienneté des services ${ }^{33}$. Cette double autorité est concevable dans le cadre d'une très bonne entente mutuelle, elle devient problématique lorsque les deux autorités ont des objectifs divergents, ce qui va très vite s'avérer.

Dès le mois de janvier, Broussaud se plaint que « les chefs russes s'en réfèrent volontiers à l'autorité du général Wrangel quand ils croient pouvoir en user pour contrecarrer [ses] ordres », ajoutant perfidement «qu'ils ne se gênent nullement pour transgresser les prescriptions édictées par le général en chef quand elles vont à l'encontre de leur paresse et de leur insouciance ». Un premier heurt a lieu lorsque Broussaud ordonne de rassembler les revolvers non employés et de les remettre aux militaires français. Fostikov répond « qu'il ne saurait exécuter les ordres reçus de l'autorité française sans être au préalable autorisé par le général Wrangel ${ }^{34}$. Informé par le général Charpy, Wrangel approuve ce refus d'obéissance :

je ne saurais sanctionner par mon silence tous les ordres qui seront donnés à l'armée en dehors de moi. En conséquence, je prescris aux commandants [...] d'aller au-devant de tous les désirs des commandants français des camps, mais je leur notifie en même temps qu'ils relèvent uniquement de moi et que pour toutes les questions de principe ils doivent se guider sur mes directives seulement. ${ }^{35}$

La guerre est déclarée.

Afin de tenter d'aplanir les difficultés, une entrevue a lieu au mois de février entre Broussaud, l'ataman du Don Naumenko, le général Fostikov et le général Artifeksov, représentant de Wrangel. Sans surprise, elle se solde par un échec. La conclusion du compte rendu qu'en fait Broussaud est amère :

Il est très net que ces gens-là entendent vivre indéfiniment à nos crochets, se soumettre aussi peu que possible aux coutumes et consignes françaises, gagner de jour en jour plus de liberté, travailler le moins possible ; voilà leur idéal. Toutes celles de mes démarches qui tendent à le contrarier sont mal accueillies et sournoisement combattues. ${ }^{36}$

C'est avec le jeune général Fostikov que ses rapports sont les plus détestables. Le portrait qu'en fait Broussaud au fil de sa correspondance n'est guère flatteur, c'est un enquiquineur fourbe :

sa tactique consiste à revenir indéfiniment sur les questions déjà réglées et il ne lui en coûte pas beaucoup de protester sa propre signature. Il ne mérite aucune confiance $^{37}$;

33. Ibid., 20 N 1228, lettre 3016/3 du général Charpy au général Wrangel, 9 janvier 1921.

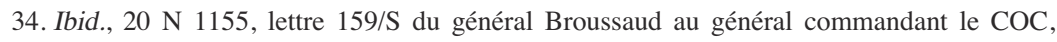
10 janvier 1921.

35. Ibid., lettre 5050 du général Wrangel au général Charpy, 10 janvier 1921.

36. Ibid., lettre 172/S du général Broussaud au général commandant le COC, 5 février 1921.

37. Ibid. 
ses sentiments anti-français sont à peine dissimulés [...] il ne laisse passer aucune occasion de nous créer des difficultés nouvelles, ${ }^{38}$

malhonnête :

Sa probité personnelle est au moins douteuse. Comment se fait-il en effet que l'état-major du Kuban', arrivé ici sans ressources, dispose maintenant de tout l'argent nécessaire pour les fêtes, le théâtre et ses autres fantaisies? Sans doute cet argent provient-il de la vente subreptice des effets volés aux Grecs de Théodosie ${ }^{39}$ et sans doute aussi de marchandises françaises ${ }^{40}[\ldots]$

C'est de surcroît un mauvais chef : «[ses] injustices continuelles [...] et sa duplicité semblent l'avoir rendu peu populaire parmi les Cosaques eux-mêmes $»^{41}$.

À partir de février, à plusieurs reprises, Broussaud demande que Fostikov soit relevé de son commandement et remplacé par un autre officier. La décision finit par être prise en avril, suite à un énième incident : Fostikov a fait libérer de force un officier russe qui avait été arrêté par les gendarmes français. L'occasion est fournie par un déplacement du général à Constantinople, accompagné de l'ataman Naumenko. Les deux hommes ne sont tout simplement plus autorisés par les Français à retourner à Lemnos ${ }^{42}$. Quant à Wrangel, toutes ses demandes d'une nouvelle visite à Lemnos se heurtent à un refus catégorique.

Le vieux général Abramov, beaucoup plus consensuel, est désigné chef russe des camps de Lemnos par le général Charpy, en remplacement de l'incontrôlable Fostikov. Dès lors, les rapports avec Broussaud se pacifient en surface. Plus policé que Fostikov, Abramov est cependant sur la même ligne que lui : selon le service de renseignements français, il qualifie dans ses rapports à Wrangel les actions de Broussaud d' « agissements provocateurs », le considère comme «très russophobe et très monté contre l'armée russe », ne «manquant pas de manifester ces sentiments à la moindre occasion ». Il l'accuse de «mettre aux arrêts les officiers russes pour des peccadilles »; bref, il dresse le tableau d'un insupportable dictateur, et demande à ce qu'il soit relevé de ses fonctions ${ }^{43}$. Les Français ne sont pas dupes des sentiments d'Abramov, mais se félicitent tout de même qu'il ait «au moins en apparence une attitude très correcte $»^{44}$

38. Ibid., lettre 177/S du général Broussaud au général commandant le COC, 15 février 1921.

39. Port de Crimée d'où a été évacué Fostikov.

40. SHAT, 20 N 1155, lettre 177/S du général Broussaud au général commandant le COC, 15 février 1921.

41. Ibid.

42. Ibid., lettre 3801/3 du général Charpy au général Wrangel, 8 avril 1921.

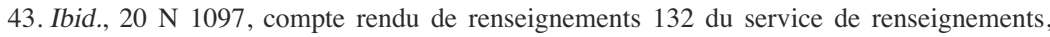
Constantinople, 14 avril 1921.

44. Ibid., 20 N 1155, rapport du COC à Paris, 17 mai 1921. 
En juin, alors que les camps se vident peu à peu et que Broussaud a été remplacé par le chef d'escadron Brun, les rapports se tendent à nouveau. Face à l'hostilité d'Abramov, Brun prend des mesures drastiques, qu'il expose franchement dans un rapport :

Une épidémie de variole dans l'île a été l'occasion de faire rentrer tout le monde dans les limites du camp. Le service de garde mal fait à l'intendance a permis d'installer un poste français au milieu du camp russe. Le prétexte de surveiller les barques grecques faisant de la contrebande a permis d'organiser un système de patrouilles dans le camp nuit et jour. Le camp a pris l'aspect d'un camp de prisonniers, le commandement russe ne s'est pas trompé sur le but poursuivi, mais à part quelques protestations sur la brutalité des tirailleurs le résultat a été obtenu. [...] Les choses se sont tassées ensuite et les rapports sont redevenus corrects.

Paradoxalement, quant à l'attitude future des Cosaques à l'égard de la France, Brun est optimiste :

Je crois que finalement elle ne sera pas hostile. Les froissements journaliers s'oublient, parmi les officiers il y a pas mal de francophiles, parmi les Cosaques beaucoup. Les officiers francophobes l'ont été de tout temps, je ne crois pas que leur séjour dans un camp de concentration ait finalement changé grand-chose..$^{45}$

\section{Les effectifs}

Les effectifs du camp de Lemnos atteignent leur apogée entre février et avril 1921 pour ensuite baisser régulièrement jusqu'à la fermeture du camp en octobre 1921 .

Effectif des camps

\begin{tabular}{|l|c|c|}
\hline & LEMNOS & TCHATALDJA \\
\hline 24 novembre 1920 & 15000 & \\
\hline 26 novembre 1920 & 17500 & 21000 \\
\hline 28 novembre 1920 & 19200 & 20302 \\
\hline 20 décembre 1920 & 17000 & 19387 \\
\hline $1^{\text {er }}$ janvier 1921 & 16220 & 11874 \\
\hline $1^{\text {er }}$ février 1921 & 21505 & 8544 \\
\hline $1^{\text {er }}$ mars 1921 & 20993 & 2841 \\
\hline $1^{\text {er }}$ avril 1921 & 20744 & 2497 \\
\hline $1^{\text {er }}$ mai 1921 & 17211 & 1891 \\
\hline 17 mai 1921 & 17056 & \\
\hline
\end{tabular}

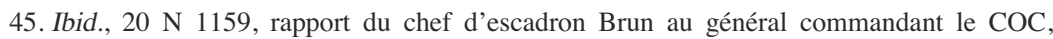
9 septembre 1921. 


\begin{tabular}{|l|c|c|}
\hline & LEMNOS & TCHATALDJA \\
\hline $1^{\text {er }}$ juin 1921 & 12629 & 1890 \\
\hline 20 juin 1921 & 7033 & 1892 \\
\hline $1^{\text {er }}$ juillet 1921 & 7033 & 1793 \\
\hline $1^{\text {er }}$ août 1921 & 4340 & 1709 \\
\hline $1^{\text {er }}$ septembre 1921 & 1764 & 1705 \\
\hline $1^{\text {er }}$ octobre 1921 & 140 & 1850 \\
\hline $1^{\text {er }}$ novembre 1921 & 0 & 1829 \\
\hline
\end{tabular}

\section{L'hébergement}

Camp du Kuban': les réfugiés du Kuban' sont hébergés dans 1700 tentes marabouts rondes, pouvant abriter une dizaine d'hommes. Elles sont peu confortables : étroites, sans chauffage, on ne peut s'y tenir debout qu'au centre, et les réfugiés dorment en rayons. On trouve souvent quatorze hommes entassés dans chaque tente, dont trois ou quatre officiers. Il y a aussi quatre-vingts grandes tentes pouvant abriter de trente à soixante hommes, mais elles servent surtout à abriter les pléthoriques états-majors, les mess d'officiers ainsi que leurs familles, les réfectoires...

Dans la plupart des cas, les hommes dorment sur le sol, d'abord sur de l'herbe et des chiffons, et à partir de janvier 1921 sur de la paille distribuée par les Français. Les grandes tentes sont équipées de l'électricité, les petites doivent se contenter de bougies et de lampes à pétrole. Le bois de chauffage n'est que très chichement distribué, et il est interdit aux Cosaques d'aller en chercher dans la nature, afin d'éviter un déboisement total de l'île.

Le camp est établi sur la côte nord-ouest de la baie de Moudros. Les cuisines, lavoirs et lavabos ont été installés au bord de la mer. Quelques efforts d'esthétique ont été consentis : les passages sont bordés de pierres blanchies. Selon le commandant du COC, « la régularité des camps ainsi établis le long du rivage [...] donne une impression d'ordre $»^{46}$. Une fois n'est pas coutume, Wrangel est d'accord avec lui : «L'aspect extérieur du camp produit une très bonne impression $»^{47}$. Toutefois, les tentes ont bien du mal à résister aux vents violents de la mer Égée.

Camp du Don : Si les Cosaques du Kuban' ont pu s'installer en plaine, ceux du Don se trouvent sur des collines parfois escarpées et séparées par des ravins. Des travaux de terrassement ont été nécessaires pour installer les camps. Les Cosaques sont hébergés dans des baraques en tôle cintrée formant des demi-tonneaux fermés aux deux extrémités par des sacs de sable, des bidons de pétrole et des caisses de conserves vides. On trouve aussi quelques grandes tentes et de petites tentes

46. SHMT, 56 C 59-60, rapport 2568/3 du général Nayral de Bourgon au haut-commissaire de la République, $1^{\text {er }}$ décembre 1920.

47. Ibid., 56 C 61-62, rapport 61 du général Wrangel, 21 février 1921. 
marabouts. Les baraques en tôle sont vastes : $2 \mathrm{~m}$ de haut au centre, $4 \mathrm{~m}$ de large. Mais il y fait très chaud en été et très froid en hiver. Des poêles bricolés avec des matériaux de fortune ont été installés par les occupants. Certains ont recouvert les tôles de terre et d'herbe pour éviter la surchauffe du métal au soleil. Contrairement aux Koubanais, la plupart des hommes disposent pour dormir de châlits ou de lits de camp. Par contre, l'entassement est assez comparable.

Des escaliers, des passages pavés et ornés ont été installés par les Cosaques pour faciliter les déplacements. Wrangel est assez impressionné lors de sa visite : «Apparemment, beaucoup d'efforts et de sollicitude ont été prodigués pour l'installation des Cosaques ${ }^{48}$.

\section{La nourriture}

Chargé du ravitaillement, le COC a dû fixer une ration quotidienne pour chaque réfugié. En décembre 1920, elle se compose de pain, farine, conserves, viande fraîche, graisse, légumes secs, sucre, café et thé. Cette ration est dès le départ inférieure à celle des soldats français en Orient. Par la suite, sur ordre du Gouvernement, dans le double but de réduire les frais et d'inciter les Russes à trouver un asile ailleurs, les autorités réduisent peu à peu la ration journalière :

\begin{tabular}{|c|c|c|c|c|c|c|c|c|c|}
\hline date & Pain & Farine & Conserves & $\begin{array}{c}\text { Viande } \\
\text { fraîche }\end{array}$ & Graisse & $\begin{array}{c}\text { Légumes } \\
\text { secs }\end{array}$ & Sucre & Café & Thé \\
\hline 13.12 .20 & $500 \mathrm{~g}$ & $150 \mathrm{~g}$ & $250 \mathrm{~g}$ & $300 \mathrm{~g}$ & $20 \mathrm{~g}$ & $100 \mathrm{~g}$ & $20 \mathrm{~g}$ & $20 \mathrm{~g}$ & $7 \mathrm{~g}$ \\
\hline 10.01 .21 & $500 \mathrm{~g}$ & $100 \mathrm{~g}$ & $200 \mathrm{~g}$ & - & $20 \mathrm{~g}$ & $100 \mathrm{~g}$ & $20 \mathrm{~g}$ & - & $7 \mathrm{~g}$ \\
\hline 1.02 .21 & $500 \mathrm{~g}$ & - & $200 \mathrm{~g}$ & - & $20 \mathrm{~g}$ & $100 \mathrm{~g}$ & $20 \mathrm{~g}$ & - & $7 \mathrm{~g}$ \\
\hline 14.02 .21 & $450 \mathrm{~g}$ & - & $200 \mathrm{~g}$ & - & $20 \mathrm{~g}$ & $90 \mathrm{~g}$ & $20 \mathrm{~g}$ & - & $7 \mathrm{~g}$ \\
\hline 10.04 .21 & $350 \mathrm{~g}$ & - & $200 \mathrm{~g}$ & - & $20 \mathrm{~g}$ & $80 \mathrm{~g}$ & $20 \mathrm{~g}$ & - & $7 \mathrm{~g}$ \\
\hline
\end{tabular}

Ces réductions entraînent les protestations de Wrangel, selon lequel « d'après le témoignage des médecins », la ration allouée est « insuffisante comme nutrition d'une personne normale et sa réduction aboutira finalement à la famine $»^{49}$. Il télégraphie même à la Société des Nations et à la Croix-Rouge pour signaler que «l'épuisement causé par l'insuffisance de nourriture a provoqué dans les camps [...] de Lemnos une épidémie de tuberculose, qui prend des proportions catastrophiques $»^{50}$. Affabulations, certes..., dont la presse se fait l'écho. Les plaintes sur la qualité et la quantité de nourriture sont assez courantes. Svidin parle

48. Ibid.

49. SHAT, 20 N 1158, lettre 6120 du général Wrangel au général Charpy, 21 avril 1921.

50. ADQO, Europe 1918-1940, URSS 265-266, Lettre 281 du général Pellé à Aristide Briand, 27 juillet 1921. 
même de «famine chronique ». Sa description de la façon de cuisiner n'est certes pas appétissante :

Voici ce que chacun de nous recevait : une boule de pain pour cinq personnes [...], une boîte de corned-beef pour quatre personnes, une cuillerée de margarine par personne, et une cuillerée de sucre avec un peu de thé. On mettait tout, sauf le sucre, dans une grande marmite, et cette « soupe » était notre seule et unique nourriture. ${ }^{51}$

Les repas sont préparés dans des cuisines de campagne. Faute de combustible, ils sont souvent servis froids. À plusieurs reprises, le Gouvernement français menace de cesser totalement le ravitaillement, mais les militaires français sur place ne cessent de souligner le caractère inapplicable de cette mesure. Les arguments ne manquent pas pour le général Charpy, qui a succédé à Nayral de Bourgon à la tête du COC :

Ce sera la famine [...] car les ressources locales, surtout à Gallipoli et à Lemnos, sont soit inexistantes, soit nettement insuffisantes pour subvenir à la subsistance d'une masse aussi considérable. Il est superflu de s'étendre sur les excès de toute nature, auxquels se livrera, sous la pression de la faim, cette masse de réfugiés dont l'état moral est loin d'être brillant [...] [Cela] produira une impression déplorable, non seulement chez ceux qui en souffriront mais chez tous ceux qui en auront connaissance [...] Tout sentiment de reconnaissance disparaîtra pour faire place à une haine implacable [...] J'estime donc que l'abandon des réfugiés russes constituerait un geste déplorable, inhumain et impolitique. ${ }^{52}$

À contrecœur, le Gouvernement doit admettre ces arguments. La mesure ne sera jamais appliquée.

\section{L'habillement}

Les réfugiés sont très mal vêtus. Ils ne disposent généralement que d'une seule tenue militaire et d'une paire de chaussures. Beaucoup n'ont ni chandail, ni couverture. Un officier français en visite constate que de nombreux Cosaques marchent nu-pieds ${ }^{53}$. Sur demande de Wrangel, ordre est donné de distribuer dans les camps de Lemnos 5000 paires de chaussures prélevées sur les cargaisons des bateaux russes $^{54}$. Malgré cette mesure, lorsque Wrangel vient visiter les camps les 18 et 19 février 1921, il ne peut passer en revue qu'un tiers des effectifs, les autres

51. Svidine, Le secret de Nicolas Svidine, p. 110.

52. SHAT, 20 N 1154, lettre 3109/S du général Charpy au ministre de la Guerre, 22 janvier 1921.

53. SHMT, 56 C 30, rapport 2962/502 CE adressé au général commandant le COC, 23 décembre 1920.

54. Ibid., 56 C 59-60, ordre 1558/4S du général Charpy, 24 janvier 1921. 
n'ayant pu défiler faute de chaussures ou d'uniformes. Dans son rapport, il accuse les Français de distribuer au compte-gouttes les stocks qu'il a rapportés de Crimée, mais il admet aussi à demi-mot qu'il a pu y avoir des détournements au sein des services russes des camps ${ }^{55}$. Les autorités françaises ont en effet remis aux Russes 50000 couvertures, 86000 caleçons, 118000 paires de chaussettes, 183000 serviettes... soit des quantités supérieures aux effectifs. Or nombreux sont ceux qui n'ont rien reçu. Comme le constate délicatement un militaire français, « il y a un gaspillage considérable des effets entre la remise aux autorités russes et la délivrance aux hommes $»^{56}$.

\section{Les coopératives}

Beaucoup de Cosaques disposant d'un peu d'argent liquide, le général Broussaud ne vit aucun inconvénient à accéder à leur demande : organiser des magasins coopératifs où ceux qui disposent d'un pécule puissent s'acheter à prix raisonnable des compléments alimentaires et vestimentaires. Plusieurs coopératives sont ainsi mises en place dans les camps. Autorisées à faire un bénéfice de $6 \%$, elles vendent nourriture, vêtements, ustensiles, couvertures... Broussaud a même donné l'autorisation de vendre des spiritueux «en petite quantité ». Peu à peu, des rumeurs désagréables parviennent aux oreilles des officiers français : les coopératives feraient bien plus que $6 \%$ de bénéfices. Afin d'en avoir le cœur net, Broussaud ordonne une enquête : les livres de comptes sont saisis, des perquisitions ont lieu dans les magasins et chez les fournisseurs grecs. En lisant les rapports, le général n'en croit pas ses yeux : en fait de coopératives, il s'agit de sociétés par actions contrôlées par des officiers du corps du Kuban' ; les dividendes atteignent $370 \%$ par mois ! Parmi les produits vendus, généralement renchéris de 20 à $30 \%$, figurent des effets français de provenance inexpliquée. Les «petites quantités » de spiritueux atteignent 649 bouteilles de cognac en un mois ${ }^{57}$ !

Après quelques arrestations, dont celle de deux officiers qui cherchaient à gagner Constantinople avec leur butin, les coopératives sont dissoutes. La nouvelle coopérative qui les remplace sera strictement encadrée par les Français. Ses bénéfices, plafonnés à $6 \%$, serviront à financer des activités culturelles ou religieuses. Interdiction est faite de retirer des bénéfices sur les denrées fournies par l'intendance française, les prix de vente sont affichés et la vente d'alcool est prohibée 58 . La fête est finie.

55. Ibid., 56 C 61-62, rapport 61 du général Wrangel, 21 février 1921.

56. Ibid., 56 C 66 bis-67, rapport de la conférence hebdomadaire du COC, 29 janvier 1921.

57. SHAT, 20 N 1155, lettre 187/S du général Broussaud au général Wrangel, 19 mars 1921.

58. Ibid., ordre 49 du général Broussaud, 19 mars 1921. 


\section{Santé et hygiène}

Les Français ont mis en place à Moudros-Ouest deux hôpitaux de campagne de 300 et 400 lits, ainsi qu'un autre de 250 lits à Moudros-Est. Ils sont sous la direction d'un médecin militaire français, avec du personnel sanitaire russe. De l'avis même de Wrangel, ils sont très bien équipés : médicaments en nombre, laboratoire d'analyses, salle d'opération, service gynécologique avec doctoresse, cabinet dentaire... Ils ne désemplissent pas, et voient même le nombre de malades augmenter : 447 hospitalisés le 5 décembre 1920, 518 le 12, 780 le 21, 789 le 26, 926 le 2 janvier 1921. Chiffres à majorer d'un quart si l'on compte les malades qui sont dans les infirmeries des régiments.

En effet, la situation sanitaire est médiocre. Si une douzaine de cas de variole et de typhoïde sont rapidement éradiqués, ceux de pneumonies sont nombreux. Le typhus surtout fait des ravages : dès l'arrivée des premiers réfugiés sur l'île, on recense deux cents cas de type récurrent et six cas de type exanthématique; fin décembre, ces chiffres ont à peu près doublé59. On compte alors de deux à trois morts par jour. Les poux sont le principal vecteur de cette épidémie. Ceux de Lemnos sont d'une étonnante résistance aux dires de Nikolaj Svidin :

Comme nous étions serrés les uns contre les autres, faute de place et aussi pour nous réchauffer, nous avons bientôt été attaqués par une véritable armée de poux. Ils nous ont fait souffrir cruellement, jour et nuit. Nous ne pouvions plus dormir. Tout le monde se grattait. Ces maudits parasites ne craignaient qu'une chose : le feu. J'avais tout fait pour en débarrasser mon linge. J'étais allé à la mer, je l'avais mis dans l'eau. Pour qu'il ne soit pas ramené par les vagues, j'avais mis dessus une lourde pierre. Et cinq jours après, j'avais pu constater que ce séjour dans l'eau froide et salée n'avait en rien affecté la vivacité de nos terribles ennemis. ${ }^{60}$

En janvier, des appareils de désinfection sont enfin installés, pouvant traiter 1000 hommes par jour. Il s'agit de fours permettant de chauffer les vêtements à $140^{\circ}$ pendant 40 minutes, afin d'éliminer la vermine ; pendant ce temps, les hommes peuvent prendre une douche avec l'eau chauffée par les fours. Dès lors, la situation sanitaire s'améliore : en avril, les militaires français la qualifient d'excellente.

Le service de santé français reçoit une aide appréciable de la part de la CroixRouge américaine, qui fournit les hôpitaux en linge, paillasses et lits. Elle donne aussi aux réfugiés des vêtements, des friandises... Sa générosité finit par agacer les Français lorsqu'elle propose de mettre en place un asile pour les femmes et enfants, un sanatorium pour les tuberculeux... Tout cela ne contribue-t-il pas à fixer les réfugiés, alors que l'obsession des militaires est d'organiser au plus vite leur dispersion vers d'autres pays susceptibles de les accueillir ${ }^{61}$ ?

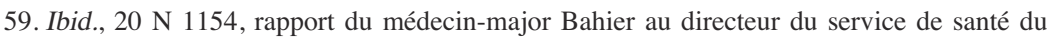
COC, 4 décembre 1920 .

60. Svidine, Le secret de Nicolas Svidine, p. 110.

61. SHAT, 20 N 1154, lettre 193/S du général Broussaud au général commandant le COC, 5 avril 1921. 


\section{Le travail}

Des ateliers de couture et de cordonnerie ont été créés pour l'entretien des tentes et des vêtements : dix-huit cordonniers et dix tailleurs s'y activent. De multiples autres ateliers sont dispersés dans les camps. On bricole aussi des couteaux à partir de sabres brisés. Le corps du génie est évidemment celui qui a l'atelier le plus complet, avec forge, menuiserie, serrurerie... Une boulangerie, mise en place par le COC, équipée de huit fours, parvient à fournir 18000 rations de pain par jour. Ceux qui savent manier la plume peuvent participer à la rédaction d'un journal, Le Courrier du Camp du Don que l'on affiche sur des colonnes au milieu du camp. Il y a aussi les corvées ordonnées par les autorités russes ou françaises. Qu'elles ne suscitent guère l'enthousiasme, est un euphémisme ! Les Français se plaignent à plusieurs reprises dans leurs écrits de la paresse des Cosaques, et parfois de leur manque d'obéissance. Broussaud relativise cependant :

il faut admettre cette circonstance atténuante que le soldat cosaque, assez borné, ne comprend pas toujours l'intérêt des travaux qui lui sont ordonnés, alors que les cadres ne se sont donnés aucune peine pour l'éclairer. ${ }^{62}$

\section{Les écoles militaires}

L'école militaire Alekseev a été installée dans le camp du Kuban', l'école Ataman au camp du Don. Elles poursuivent leurs cours, formant imperturbablement des officiers pour une armée battue qui n'a plus de pays. Leurs effectifs ne sont pas négligeables : l'école Ataman compte 450 élèves et... 53 officiers instructeurs ! Dans ces écoles, une grande tente ou une baraque sert de salle de cours, et les élèves sont logés tout autour dans de petites tentes. Chacune a son église ; celle de l'école Alekseev a été improvisée par les élèves avec des icônes récupérées dans un monastère grec en ruine, et des objets du culte improvisés. L'école du Don a même installé un petit stade de gymnastique.

\section{Le problème des armes}

Les réfugiés sont arrivés à Constantinople avec tout leur armement : il fallait laisser le moins de choses possible aux rouges, garder les armes pour reprendre la lutte au plus vite... Les autorités françaises ne l'entendent évidemment pas ainsi : dès leur arrivée, les soldats sont désarmés, et les armes entreposées à l'arsenal de San Stefano.

Des exceptions sont toutefois tolérées : les officiers gardent leurs sabres ; ceux qui ont un commandement sont autorisés à porter un pistolet. Afin de former des détachements de garde et de police, des fusils ont été laissés à raison de

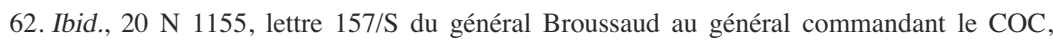
8 janvier 1921 . 
20 pour 1000 hommes. Enfin, les Cosaques ont pu garder leur poignard, le retrait de cette arme étant considéré au Kuban' comme un outrage grave.

Très rapidement pourtant, il paraît évident que de nombreuses armes ont été dissimulées : des attaques à main armée contre des habitants de l'île sont signalées. Les incidents de Tchataldja prouvent qu'une révolte contre les Français n'est pas impossible.

En janvier 1921, Broussaud ordonne au général Fostikov de désarmer les hommes et officiers subalternes, à l'exception des poignards et sabres. Les fusils destinés au maintien de l'ordre seront « inventoriés, réunis à part et soigneusement gardés en dehors des prises d'armes ${ }^{63}$. La mauvaise volonté de Fostikov aidant, les résultats ne sont guère convaincants : un mois plus tard, les autorités russes admettent qu'il y a dans les camps de Lemnos 500 fusils (soit 100 de trop), 232 revolvers, 12 mitrailleuses et... 4 canons $^{64}$ ! Encore sommes-nous en droit de supposer que ces chiffres officiels sont fortement minorés. Une action par la force, envisagée pendant un moment par le COC pour confisquer les armes, est abandonnée en raison des risques d'affrontements.

\section{La garde de Broussaud}

Lorsque le général Broussaud dirigeait la mission militaire française en Crimée, Wrangel lui attribua une garde d'honneur cosaque. Avait-elle été oubliée par le baron ? Toujours est-il qu'il n'annula jamais cet ordre et que la garde de Broussaud le suivit comme un chien fidèle, dans l'évacuation de la Crimée à bord du Waldeck Rousseau, puis à Lemnos. C'était une sotnia ${ }^{65}$ irrégulière de montagnards, commandée par l'essaoul Slobodinskij. Si les huit officiers étaient orthodoxes, les dix-neuf sous-officiers et soixante dix hommes de troupe se partagaient entre Cosaques du Terek musulmans et Kalmouks bouddhistes. Broussaud s'était débrouillé pour leur faire attribuer une petite solde ; il faut dire que, face au petit nombre de soldats français dont il disposait et à l'hostilité grandissante des officiers russes, ces gardes du corps lui étaient bien utiles.

Dans ses écrits, Broussaud montre une véritable tendresse pour ces hommes qui lui sont totalement dévoués. Il les décrit comme des «soldats magnifiques » dont beaucoup sont âgés et couverts de blessures, presque tous décorés de l'ordre de Saint-Georges ${ }^{66}$. À plusieurs reprises, il se préoccupe de leur devenir, soulignant le fait qu'il serait peu souhaitable de les incorporer dans la Légion étrangère car « trop lointains de notre civilisation et dépourvus d'individualité », ressemblant plus à une «famille militaire » qu'à un corps de troupe, et risquant de tomber «à l'état

63. SHMT, 57 C 27, lettre 991 du général Broussaud au général Fostikov, 4 janvier 1921.

64. SHAT, 20 N 1228, lettre 3288/3 du général Charpy au général Wrangel, 8 février 1921.

65. Une sotnia se compose d'une centaine d'hommes.

66. SHAT, 20 N 1154, lettre 775 du général Broussaud au général commandant le COC, 11 décembre 1920. 
d'épaves si les liens de service qui les rattachent entre eux et à leurs chefs étaient brisés » ${ }^{67}$. Il ajoute : «Le dévouement que ces montagnards témoignent à ma personne les rend presque hostiles aux Russes eux-mêmes, ce qui rendrait leur situation ici difficile après mon départ ${ }^{68} »$.

Lors de sa visite sur l'île, le général Nayral de Bourgon passe cette garde en revue ; douze ans plus tard, dans ses Mémoires, il en conserve encore un souvenir précis :

Cette courte revue me permit d'admirer l'excellent état de propreté des armes, la correction extérieure, malgré des vêtements très usagés, mais entretenus, contrastant avec la crasse des visages, d'où se pouvait déduire celle des parties non apparentes du corps dépourvues sans doute de toute espèce de linge. Le contraste révélait une bonne troupe, persistant dans ses devoirs militaires en dépit de la misère générale. ${ }^{6}$

Deux ans plus tard, devenu responsable de l'artillerie en Algérie, Broussaud continuera à se démener pour trouver un asile à l'essaoul Slobodinskij, réfugié en Bulgarie, « à qui ses compatriotes reprochent amèrement d'avoir servi la cause française » ${ }^{70}$.

\section{La discipline}

Maintenir la discipline d'une telle masse de réfugiés est une gageure. Selon Wrangel, c'est surtout le corps du Kuban' qui témoigne d'indiscipline, et les officiers en sont les premiers responsables :

Il est visible qu'il n'y a pas d'ordre dans le corps ; l'ordre du commandant de corps n'est pas respecté par les commandants d'unités; les officiers ne surveillent pas leurs unités et, lorsque les Cosaques ont commis des méfaits graves, au lieu d'en référer aux chefs et les aider ainsi à punir les coupables, ils couvrent ceux-ci. ${ }^{71}$

Le service de renseignements russe confirme cette assertion. Broussaud va plus loin, en mettant directement en cause le chef du corps, le général Fostikov :

son corps n'est aucunement discipliné, $[\ldots]$ le vol et la paresse y fleurissent sous les yeux du chef de corps qui vraisemblablement profite des larcins commis à notre détriment. ${ }^{72}$

67. Ibid., $20 \mathrm{~N}$ 1155, lettre 896 du général Broussaud au général commandant le COC, 24 décembre 1920.

68. Ibid., lettre 1118 du général Broussaud au général commandant le COC, 17 janvier 1921.

69. Nayral de Bourgon, 10 ans de souvenirs, p. 171-172.

70. ADQO, Europe 1918-40, URSS 268, lettre manuscrite du général Broussaud au président du Conseil, 9 février 1922.

71. SHAT, 20 N 1138, prikaz 62 du général Wrangel, 24 février 1921.

72. SHMT, 56 C 61-62, lettre 190/s du général Broussaud au général commandant le COC, 29 mars 1921. 
Selon le service de renseignements russe, le corps du Don se comporte mieux, mais l'ivresse y est monnaie courante.

L'incertitude sur le sort de l'armée est une des sources de ce problème : si l'armée semble devoir être dissoute à brève échéance, à quoi bon travailler et faire des exercices ? Avec le temps et les départs, l'insubordination a tendance à augmenter du fait que ce sont les unités les plus disciplinées qui ont été les premières choisies pour partir. En juin 1921, le service de renseignements français constate que « de plus en plus [...], les Cosaques échappent à l'autorité de leurs chefs »; ainsi un officier français en tournée dans les camps rapporte ces propos d'un important groupe de Cosaques :

Nous ne voulons plus supporter l'autorité de nos chefs qui nous exploitent et nous mentent. Que le général Broussaud nous envoie le dernier de ses soldats nègres et nous le suivrons, mais nous ne voulons pas obéir au général Abramoff.

Selon le service de renseignements, la plupart «n'aspirent qu'à se faire démobiliser $\gg^{73}$. En effet, une commission russe de démobilisation fonctionne afin d'éliminer de l'armée les indésirables. Wrangel a demandé à ce que les démobilisés quittent Lemnos et aillent dans les camps civils de Constantinople, ce qui a été refusé par les autorités françaises. Les démobilisés sont installés séparément afin d'éviter les incidents, mais traités de la même manière que les militaires (nourriture, vêtements...) afin de ne pas donner de prime à ceux qui resteraient fidèles à Wrangel.

\section{La délinquance}

Au sein des camps, de nombreux vols sont signalés dans les magasins. Broussaud est assez désabusé en ce qui concerne la moralité des troupes : «Le pillage, le vol et le mensonge sont permanents et à tous les degrés ${ }^{74}$. Ne disposant pas de troupes françaises suffisantes, il a dû se résoudre à confier la garde des magasins au corps russe qui lui inspirait le plus confiance, l'école des cadets élèves officiers. La suite est racontée dans un rapport français :

Ce corps d'élite, justement fier de cette désignation, estima, selon la méthode russe, qu'un poste de confiance ne justifie sa valeur que s'il procure des avantages. Ainsi les cadets, fracturant les clôtures [...] firent-ils main basse sur les approvisionnements de l'intendance qu'ils transportèrent dans leurs tentes, sans même prendre la peine de les dissimuler, tellement la chose leur semblait naturelle et normale..$^{75}$

73. SHAT, 20 n 1158, rapport 222/S du capitaine Perret, 7 juin 1921.

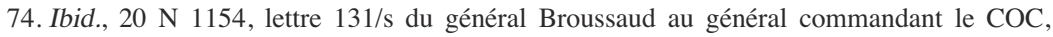
5 décembre 1920 .

75. SHMT, 56 C 59-60, rapport de mission d'auteur inconnu, 31 décembre 1920. 
Selon les agents russes de renseignement, les services d'intendance ne sont pas en reste :

Les détournements [...] prennent des proportions inquiétantes; l'intendance russe n'hésite pas, en présence des réclamations qui se font entendre, à rejeter la faute sur l'intendance française [...]. Les officiers russes employés aux différents services de l'intendance font fréquemment face à des dépenses qui sont certainement au-dessus de leurs moyens. ${ }^{76}$

Un exemple parmi d'autres : deux officiers sont arrêtés pour avoir grossi les effectifs dont ils étaient responsables afin de revendre l'excédent de rations alimentaires ${ }^{77}$. Nombreux sont les officiers qui demandent une permission pour aller dépenser leur argent à Constantinople. Conscient que cet argent a été amassé «par des moyens difficiles à expliquer », Broussaud finit par leur interdire cette possibilité au mois d'avril $1921^{78}$.

À l'extérieur des camps, les méfaits sont plus nombreux encore. On recense de nombreux vols «alimentaires »: farine, bétail, alcool, tabac, etc. Parfois, ces méfaits tournent au vandalisme pur et simple ou au pillage organisé ; ainsi, à l'occasion d'une marche militaire du 1 $1^{\text {er }}$ régiment du Kuban', un bivouac est organisé pour la nuit au village de Kroumos. S'en suivent le pillage d'un magasin, des vitres brisées, une tentative de rentrer en force dans une maison du village ${ }^{79}$. Les vols de bateaux, assez courants, sont le fait de déserteurs cherchant à quitter l'île. Certains gagnent ainsi l'île d'Imbros, où ils sont arrêtés. Bien plus grave, certains déserteurs deviennent meurtriers : un habitant du nord de Kastro est assassiné, un autre blessé en janvier $1921^{80}$; le mois suivant, ce sont deux bateliers qui subissent le même sort $^{81}$. Laissons toutefois la conclusion au général Nayral de Bourgon : «De tels incidents sont possibles avec les meilleures troupes et 20000 coloniaux français en auraient fait bien plus en pareil cas $»^{82}$.

76. SHAT, $20 \mathrm{~N}$ 1155, rapport 12 du service de renseignements russe de Lemnos, 6 mars 1921. 77. SHMT, 56 C 66bis-67, compte rendu de la conférence hebdomadaire du COC, 26 mars 1921.

78. SHAT, 20 N 1158, lettre 1582 du général Broussaud au général commandant le COC, 3 avril 1921.

79. Ibid., 20 N 1138, prikaz 62 du général Wrangel, 24 février 1921.

80. Ibid., $20 \mathrm{~N}$ 1155, télégramme 1480 du général Broussaud au général commandant le COC, 4 janvier 1921.

81. Ibid., 20 N 1155, lettre 1329 du général Broussaud au général commandant le COC, 15 février 1921.

82. SHMT, 56 C 59-60, rapport 2568/3 adressé au haut-commissaire français à Constantinople, 1 er décembre 1920. 


\section{Les relations entre Cosaques et Grecs}

Dès leur arrivée sur l'île, les réfugiés se voient signifier par les Français l'interdiction de se rendre dans les villages grecs. Dans une lettre au commandant russe du camp, le général Broussaud justifie cette mesure très impopulaire par trois motifs. Tout d'abord, les maladies contagieuses qui règnent dans le camp : «il n'est pas possible d'admettre que je laisse exposée à la contamination une population paisible dont nous sommes les hôtes forcés ». Il souligne ensuite l'absence de solde pour les Cosaques, qui ne peuvent ainsi faire d'achats : «certains éléments peu scrupuleux en profitent pour ne pas payer, les autres se défont à vil prix d'objets de valeur qu'ils auraient tout intérêt à conserver pour l'avenir ». Enfin, il évoque les risques de dérapages inflationnistes :

les ressources de l'île sont très restreintes, et si les Russes munis de fonds suffisants avaient liberté absolue d'acheter dans les villages, les prix monteraient aussitôt dans des conditions fantastiques, ce qui rendrait très difficile la situation des habitants non commerçants, et serait aussi très désavantageux pour les Russes acheteurs. ${ }^{83}$

Avec l'amélioration de la situation sanitaire, l'interdiction est assouplie. Dès lors, les relations entre Cosaques et habitants de l'île sont surtout d' " affaires »; et ce, au grand dam de Broussaud, qui comprend bien que ces trafics se font surtout avec des denrées fournies par l'intendance française :

En arrivant ici, les Koubanais n'avaient pas le sou. Aujourd'hui, ils ne savent comment dépenser leur argent et leur coopérative fait mille drachmes d'affaires par jour. D'où peut venir cet argent, sinon de ventes illicites ?84

Ainsi, avec la complicité des chefs de poste russes chargés de surveiller la sortie du camp, l'intendant de la 2e division du Kuban' va vendre du thé et de la farine dans les villages des environs ${ }^{85}$. Selon Broussaud, ces postes de garde sont de vraies passoires :

Il est avéré que la plupart des sorties illicites du camp sont dues à l'insouciance (pour ne pas dire plus) du service de garde. Je constate, chaque fois que je sors, que les postes n'exécutent aucunement leur consigne et laissent passer qui que ce soit, sur le vu de n'importe quel papier, ou même sans en demander aucun ${ }^{86}$.

83. SHAT, $20 \mathrm{~N}$ 1154, lettre 681 du général Broussaud au général Fostikov, 30 novembre 1920.

84. Ibid., $20 \mathrm{~N}$ 1155, lettre 172/S du général Broussaud au général commandant le COC, 5 février 1921 .

85. Ibid., rapport du capitaine Perret, 23 mars 1921.

86. Ibid., lettre 1329 du général Broussaud au général commandant le COC, 15 février 1921. 
Ces trafics augmentent fortement avant les départs vers la Serbie ou la Bulgarie : les Cosaques sur le départ vendent plus que jamais aux Grecs tous les tissus, vivres ou médicaments qu'ils peuvent subtiliser à l'intendance russe. De nombreux Grecs venus trafiquer dans les camps doivent être expulsés par les soldats français. Une descente de police militaire française dans la ville de Kastro, aboutit à l'arrestation en flagrant délit de deux commerçants ${ }^{87}$. À la demande des Français, la police grecque participe à la traque. En mars 1921, 3 officiers russes sont arrêtés dans le village de Kondia pour avoir tenté de vendre des effets militaires ${ }^{88}$.

Un mois après leur arrivée, les Cosaques obtiennent l'autorisation d'aller participer aux travaux agricoles de l'île. Pour éviter une exploitation abusive, Broussaud fixe des conditions strictes: les Russes doivent être logés, nourris, et payés au moins deux drachmes par jour ${ }^{89}$. Il n'empêche que de nombreux déserteurs travaillent pour des Grecs à des conditions bien moins avantageuses. Des patrouilles russes envoyées dans les villages environnants pour les rapatrier au camp font bonne pêche : en une journée de décembre, 24 déserteurs sont pris, 17 le lendemain, dont bon nombre d'officiers. Ceux-ci sont immédiatement désarmés car plusieurs vols à main armée ont déjà été perpétrés par des déserteurs, et les revolvers sont une des principales marchandises trafiquées avec les Grecs.

Les échanges furent aussi culturels. Si l'on en croit Jak Deleon, écrivain turc d'origine russe :

Au bout d'un moment, les Cosaques introduisirent leur culture parmi les îliens. Les chansons russes étaient chantées dans les tavernes et le Kasachok était dansé sur les rives de l'île. Les Cosaques [...] formèrent des chœurs d'église [...] et, par la variété de leurs activités, contribuèrent à de grands échanges dans la vie sociale de la région. ${ }^{90}$

\section{Départs et fermeture des camps}

\section{Les premiers départs}

Les camps de Lemnos ne sont que peu concernés par les premiers départs de réfugiés vers les pays d'accueil. Le 12 décembre 1920, l'Austria, qui doit amener quelque 5000 réfugiés en Serbie, fait une escale à Moudros pour embarquer les membres du gouvernement du Kuban', c'est-à-dire 323 personnes en comptant les

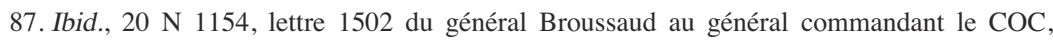
$1^{\text {er }}$ mars 1921.

88. SHMT, 57 C 27, ordre 52 du général Broussaud, 28 mars 1921.

89. SHAT, 20 N 1155, lettre 861 du général Broussaud au sous-préfet de Lemnos, 20 décembre 1920 .

90. Jak Deleon, The White Russians in Istanbul, Cagaloglu, Istanbul : Remzi Kitabevi Publications, 1995. 
familles. Les autorités françaises ne cachent pas leur satisfaction face au départ de ces personnalités jugées «assez encombrantes » ${ }^{91}$. Une semaine plus tard, le 20 décembre, c'est le Kherson qui vient embarquer 566 personnes pour la même destination. Puis... tout s'arrête. Plus aucun pays n'accepte de recevoir des réfugiés de l'armée Wrangel. Lemnos semble être une impasse totale pour les Cosaques.

\section{Les retours en Russie}

Dès lors, le mal du pays va commencer à frapper les Cosaques. Début janvier, le général Charpy croit savoir que de nombreux réfugiés demandent à rentrer en Russie «avant même que les Soviets n'aient pris officiellement aucun engagement ». Le chef du COC se félicite de cette opportunité : il donne pour consigne de les satisfaire au plus vite, « afin de ne pas laisser le temps aux propagateurs de faux bruits d'impressionner défavorablement les réfugiés qui désirent être rapatriés ${ }^{92}$. Ordre est donné aux commandants français des camps de faire savoir aux réfugiés « que le gouvernement français, loin de chercher à les retenir ne voit que des avantages au rapatriement [...] du plus grand nombre possible de réfugiés ». Tout à sa préoccupation de disperser au plus vite ces réfugiés qui coûtent cher au Trésor français, Charpy ne s'inquiète pas un instant dans sa correspondance du sort qui attend ces «contre-révolutionnaires » dans la Russie des Soviets.

En application de cette consigne, Broussaud demande à Fostikov de recenser les volontaires au retour, précisant que « des démarches sont entreprises afin de leur faire accorder des garanties pour la sécurité de leur personne $»^{93}$. Les volontaires seront démobilisés et désormais considérés comme réfugiés civils en attendant leur départ. Fostikov fait procéder au recensement le 25 janvier, mais publie dans la foulée un ordre qui fait s'étrangler Broussaud :

[...] Je vous préviens que le commandant en chef [Wrangel], le gouvernement du Kouban, l'ataman et moi [...] ne pouvons prendre aucune responsabilité vis-à-vis de ceux qui désirent regagner la Russie [...] et aucune garantie de sécurité ne peut être donnée. Le gouvernement français est du même avis. Le passage des militaires du corps dans la catégorie des réfugiés avait été envisagé à condition d'un nombre restreint de volontaires, car l'on pouvait supposer que ce nombre ne comprendrait que des personnes évacuées de Crimée accidentellement ou contre leur volonté $[\ldots]$. Or [...] il se trouve que le nombre des volontaires est assez important, ce que j'attribue à leur ignorance des choses $[\ldots]$.

91. SHMT, 56 C 59-60, lettre 2566/3 du chef d'EM du COC au vice-amiral de Bon, $1^{\text {er }}$ décembre 1920.

92. Ibid., 56 C 61-62, lettre 3249/3 du général Charpy au vice-amiral commandant en chef de l'EMOR, 4 janvier 1921 .

93. SHAT, 20 N 1155, note 1138 du général Broussaud, 18 janvier 1921. 
En conséquence, Fostikov annonce que seuls les réfugiés civils pourront retourner en Russie ; quant aux militaires,

ceux qui auront exprimé le désir de rentrer en Russie [...] resteront dans leurs unités et continueront à servir comme auparavant. Tous ceux qui se déroberont au service ou aux travaux, après s'être fait inscrire, ou ne se soumettront pas aux ordres, ou bien feront de la propagande $[\ldots]$ seront arrêtés $[\ldots]$ comme individus cherchant à entraver la continuation de la lutte contre les Bolcheviks [...] ${ }^{94}$

La réaction amère de Fostikov est compréhensible : 6931 hommes ont fait savoir qu'ils souhaitaient rentrer en Russie, soit presque $40 \%$ de l'effectif des camps de Lemnos. Dans le camp du Kuban', c'est-à-dire dans le fief même de Fostikov, la proportion atteint $50 \%$ !

Lors d'une entrevue orageuse, Fostikov dit à Broussaud que laisser partir les volontaires entraînerait la dissolution du corps du Kuban', opinion partagée par son interlocuteur :

Il est certain que si la propagande et le choix étaient libres, tous les hommes de troupe partiraient, laissant en plan quelque 3000 officiers ou soi-disant tels.

Les avis divergent cependant sur les causes :

Fostikoff explique cet exode par les menaces des propagandistes, qui insinueraient que les familles de tous ceux qui ne rentreront pas seront exterminées et par la faiblesse d'esprit des Cosaques, de grands enfants. Je serais tenté d'y voir la désaffection des hommes pour des officiers incapables, sans dignité de vie, menteurs, jouisseurs et voleurs, et le dégoût du régime qui les tolère.

Broussaud s'insurge des mauvais traitements que font subir les officiers russes aux candidats au retour : « on leur retire leurs vêtements, leurs couvertures, leurs rations sont réduites et il y a même eu des voies de fait ». En réponse, Fostikov menace de « supprimer» les 100 ou 150 « agitateurs » qui «font de la propagande » pour le retour au pays, ce à quoi Broussaud rétorque qu'en ce cas, il n'hésitera pas à avoir recours aux canons de l'aviso stationnaire. Finalement, il obtient de son interlocuteur la vague promesse que les volontaires ne seront pas inquiétés. Prévoyant que l'embarquement des volontaires risque de se faire dans la violence, il réclame des renforts en hommes et navires de guerre, qu'il n'obtiendra pas. Dépité, il conclut son rapport par ces mots : «Nous sommes sur la corde raide »96. La bataille pour la survie de l'armée Wrangel vient de commencer. Visiblement tous les coups vont être permis. Wrangel et son état-major cherchent en fait à négocier directement avec la

94. Ibid., prikaz 31 du général Fostikov, 28 janvier 1921.

95. SHMT, 57 C 27, note 69 du lieutenant de vaisseau Gaudin de Villaine au vice-amiral commandant en chef de l'EMOR, 6 février 1921

96. SHAT, 20 N 1155, lettre 176/5 du général Broussaud au général commandant le COC, 9 février 1921. 
Serbie, la Bulgarie, la Tchécoslovaquie et la Hongrie pour que ces pays acceptent des contingents qui garderaient un statut militaire, prêts à reprendre la lutte à la première occasion favorable. Un retour massif en Russie ruinerait ce plan.

La France ne reconnaissant pas le Gouvernement soviétique, c'est la CroixRouge qui est chargée de prendre contact avec les autorités russes. Le 20 janvier, le président du CICR envoie un télégramme à Čičerin, commissaire aux Affaires étrangères de Moscou, pour lui demander «d'autoriser et de faciliter le retour de tous les ressortissants russes qui désirent regagner leur pays ${ }^{97}$. Le message reste sans réponse. Une autre stratégie est alors adoptée : mettre les Soviets devant le fait accompli en leur expédiant un bateau de réfugiés, d'où un délégué leur enverra un télégramme suppliant de les accueillir.

\section{Le premier rapatriement à Novorossijsk}

Les volontaires sont trop nombreux pour que l'on puisse les embarquer sur un seul bateau. Aux quelque 7000 de Lemnos s'ajoutent 2800 Cosaques du Don du camp de Tchataldja. À la demande de Wrangel, ce sont eux qui sont désignés prioritairement pour s'embarquer sur le premier bateau. Il reste quelque 500 places pour ceux de Lemnos, attribuées à des Cosaques du Don.

Le 12 février, les premiers 558 hommes de Lemnos quittent Lemnos pour la mère Patrie. Un marin français note sobrement : «L'embarquement des passagers s'est fait dans le plus grand calme, tant chez les partants que chez ceux dont le passage a été refusé faute de place ${ }^{98}$. Un télégramme signé par les délégués est expédié aux commissaires du peuple du Gouvernement soviétique :

Environ 2000 réfugiés cosaques ${ }^{99}$ demandent rentrer dans leur patrie par Novorossisk. Bâtiment effectuant transport se présentera point arraisonnement devant Novorossisk 15 février. Ils vous demandent si pourront débarquer Novorossisk. Sont désarmés. ${ }^{100}$

Après quelques coups de canon trop courts, quelques pourparlers arrosés de vodka et de longs interrogatoires, les passagers sont autorisés par les Soviets à débarquer. Après ce premier succès, un nouveau rapatriement est programmé pour la fin mars : les autorités soviétiques ont fait savoir qu'elles étaient prêtes à recevoir un nouveau contingent à Odessa.

97. ADQO, Europe 1918-1940 URSS 259, radio de Ador pour Čičerin, 20 janvier 1921.

98. SHMT, 57 C 27, rapport nº 6 du lieutenant de vaisseau Le Luc pour le vice-amiral commandant en chef de l'EMOR, 12 février 1921.

99. En réalité 3370.

100. SHMT, 56 C 61-62, lettre 3312/3 du général Charpy au vice-amiral commandant en chef de l'EMOR, 10 février 1921. 


\section{Le second rapatriement à Odessa}

Une semaine après les premiers départs vers Novorossijsk a lieu la visite de Wrangel à Lemnos. Au cours de ses harangues aux troupes, le général affirme qu'il ne retient personne tout en fustigeant ceux qui ont voté pour le retour en Russie ; constat du commandant du stationnaire : «Il résulte de cette visite que les candidats au rapatriement se sont fait rayer des listes en très grand nombre ${ }^{101}$. Parallèlement, selon le service de renseignements français, une circulaire secrète de l'étatmajor russe charge les commandants des camps de lutter contre la propagande en faveur du rapatriement en disant que les bolcheviks ne donnent aucune garantie à ceux qui rentrent ${ }^{102}$, ce qui d'ailleurs n'est pas faux. Les résultats de cette « contreoffensive » russe sont sensibles, selon le service de renseignements russe :

Le nombre des volontaires pour la Russie soviétiste est réduit à un chiffre insignifiant; il serait d'environ 1000 hommes pour tout le corps du Kouban. Ces hommes sont réunis en un groupe isolé, soumis à un régime défavorable et surveillé étroitement. ${ }^{103}$

Le 16 mars, Broussaud reçoit une délégation de ces volontaires afin de les informer de la réussite du premier rapatriement. Il en profite pour les interroger sur les brimades qu'ils subiraient de la part des officiers ; les Koubanais confirment : «On ne nous donne ni linge, ni chaussures, et beaucoup d'entre nous doivent marcher pieds nus »; il cherche ensuite à savoir si d'autres Cosaques restés dans les régiments souhaiteraient rentrer en Russie :

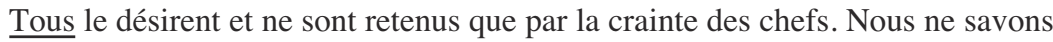
pas le sort qui nous attend là-bas, mais c'est l'amour de la terre natale qui nous attire, toutes questions de politique mises à part.

Broussaud fait immédiatement un compte rendu de l'entretien à Charpy, qu'il conclut par ces mots :

Il est pour moi certain que le jour où la consultation des Cosaques se ferait librement, sous la protection des baïonnettes françaises et en la présence sur rade du bâtiment chargé de les transporter, le plus grand nombre d'entre eux demanderaient à partirin 104

Au sortir de cet entretien, cinq des interlocuteurs de Broussaud sont arrêtés sur ordre de Fostikov, officiellement pour révolte, refus de travailler et jet de pierres

101. Ibid., 57 C 27, rapport $n^{\circ} 12$ du lieutenant de vaisseau Le Luc pour le vice-amiral commandant en chef de l'EMOR, 24 février 1921.

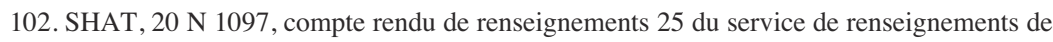
Constantinople, 2 mars 1921.

103. Ibid., $20 \mathrm{~N}$ 1155, rapport du service de renseignements russe Lemnos n 12, 6 mars 1921 . 104. Ibid., lettre 1464 du général Broussaud au général commandant le COC, 16 mars 1921. 
contre des officiers. Mal vêtus et mal chaussés, ils sont envoyés travailler à l'extérieur alors que le temps est « épouvantable » selon Broussaud, et que personne ne travaille ce jour-là 105 .

Face à cette obstruction systématique, et contrairement à ce qui avait été fait lors du premier rapatriement, décision est prise par les autorités françaises d'embarquer lors du prochain voyage tous les volontaires qui le souhaitent, sans tenir compte de l'avis de Wrangel et de ne prévenir les réfugiés que 24 heures avant le départ. Deux gros bâtiments sont prévus à cet effet, capables de transporter au total plus de 6000 hommes ${ }^{106}$.

Les opérations sont menées de manière parfaitement militaire. Le 25 mars, le Rechid Pacha mouille devant Lemnos : il vient d'amener le dernier contingent de Cosaques du Don de Tchataldja. Le lendemain, 26 mars, soit 24 heures avant le départ, Broussaud fait afficher dans les camps l'avis suivant :

Le général Charpy, commandant le COC, me communique ce qui suit : Le hautcommissaire de la République française en Orient a fait connaître au général Wrangel que le gouvernement a décidé de supprimer à bref délai tout crédit pour l'entretien des réfugiés russes. Il lui a signalé également que le gouvernement français n'était disposé ni à favoriser, ni même à tolérer une nouvelle entrée en action de l'armée Wrangel, contre le pouvoir des Soviets.

Le général Wrangel a été avisé que, dans ces conditions, les réfugiés devaient choisir entre les 3 alternatives ci-après : 1 - rentrer en Russie Soviétique ; 2 se rendre au Brésil ; 3 - subvenir eux-mêmes à leur entretien.

La situation étant nettement posée, il y a lieu de cesser toute distinction entre réfugiés civils et militaires et d'accepter les uns comme les autres s'ils manifestent le désir d'être dirigés vers l'un des débouchés offerts.

Des renseignements reçus jusqu'ici par le gouvernement français, il résulterait que $[\ldots]$ les hommes déjà envoyés à Novorossisk auraient été bien reçus et qu'il ne leur aurait pas été fait de mal. [...]

Ceci posé [...], les commandants des camps de Moudros est et ouest voudront bien porter le présent ordre à la connaissance de leurs subordonnés et me faire connaître pour demain soir $18 \mathrm{~h}$ et plus tôt si possible le nombre d'hommes volontaires pour la Sovdépie [...].

Liberté entière d'opinion doit être réservée à tous, ceux qui tenteraient d'attenter à cette liberté seraient tenus pour responsables vis-à-vis de l'autorité française. Le présent ordre sera lu aux troupes dans son intégralité et affiché dans les camps. ${ }^{107}$

Aussitôt, la contre-propagande russe se met en place, ainsi que le décrit Broussaud :

Ce ne furent que promenades dans les camps, harangues, hourrahs, bastringue, bref toute la mise en scène ordinairement employée pour leurrer ces peuplades impressionnables. ${ }^{108}$

105. Ibid., lettre 186/5 du général Broussaud au général commandant le COC, 18 mars 1921.

106. SHMT, 56 C 61-62, télégrammes 3610 et 3611 du chef d'EM du COC au général Broussaud, 20 mars 1921.

107. Ibid., 57 C 27, lettre 1515 du général Broussaud au général commandant le corps du Don.

108. Ibid., 56 C 61-62, lettre 190/S du général Broussaud au général commandant le COC, 29 mars 1921. 
Les officiers font courir plusieurs bruits : la Serbie et la Crête vont accepter bientôt des réfugiés, les États-Unis vont se charger du ravitaillement... L'ataman du Kuban' donne l'ordre à ses troupes de ne pas partir. Plusieurs officiers brutalisent des volontaires ${ }^{109}$. Pendant ce temps sont embarqués 1430 volontaires démobilisés depuis plusieurs semaines dans l'attente de leur départ. On embarque aussi 500 volontaires qui se présentent d'eux-mêmes à l'appontement. Près de 1100 Cosaques du Don venus de Tchataldja se sont portés volontaires et n'ont pas débarqué. Le lendemain, dès 8 h 30, le capitaine Michelet, escorté par quinze matelots armés et quatre gendarmes à cheval, se présente devant tous les cantonnements pour demander aux hommes s'ils ont eu communication de l'ordre de Broussaud et leur répéter qu'ils sont libres de partir. Ceux qui expriment le désir de rentrer en Russie sont invités immédiatement à réunir leurs effets personnels et à partir sans délai au port pour embarquer. La consigne est de réprimer immédiatement tout cri ou geste injurieux ${ }^{110}$. L'efficacité de la démarche se révèle bien relative selon un observateur français :

Il fut facile de constater que le procédé employé n'était susceptible de donner que d'assez faibles résultats : les hommes qui seraient volontaires n'osent pas sortir du rang, devant leurs camarades moqueurs et leurs chefs hostiles. On les sent stylés d'avance : à la fin de l'allocution de l'officier, tout le monde crie avec un ensemble parfait, comme à un commandement: Nous voulons rester à l'armée Wrangel !111

Au camp du Kuban', Michelet fait un parcours pittoresque qu'il décrit longuement dans ses rapports. Il est suivi pas à pas par Fostikov et une trentaine d'officiers russes armés. Dans les unités «sûres », l'accueil a été bien préparé ; ainsi le régiment de la garde demande d'une seule voix à partir... en Allemagne : «cette réponse collective provoqua parmi les témoins, officiers et dames de l'état-major [...] une explosion de satisfaction et de goguenardise, aussitôt couverte par le déclenchement de l'inévitable musique ». À l'école Alekseev, aucun volontaire, ce qui n'a rien d'étonnant :

À peine avais-je fini avec les cadets, ceux-ci en signe de dévouement à leur commandant d'école, le général Lebedeff, le firent sauter en l'air à la mode russe avec de retentissants hourras.

Deux officiers expliquent alors à Michelet que les vrais Cosaques ne retourneront en Russie que les armes à la main :

Pour couper court à cet exposé oiseux et maintes fois entendu, je répondis à ces deux officiers que si leurs Cosaques avaient une telle démangeaison d'avoir les

109. SHAT, 20 N 1155, rapport du capitaine Bouriand, 1 $1^{\mathrm{er}}$ avril 1921.

110. SHMT, 57 C 27, ordre 50 du général Broussaud, 26 mars 1921.

111. SHAT, 20 N 1155, rapport du capitaine Bouriand, 1 ${ }^{\mathrm{er}}$ avril 1921. 
armes à la main, ils auraient dû mieux s'en servir en Crimée. ${ }^{112}$ (Cette saillie provoquera une protestation officielle de Wrangel.)

Les incidents sont systématiques lorsque des volontaires se déclarent :

Les [volontaires] sont violemment pris à partie par leurs camarades et leurs chefs qui les accusent d'avoir volé des effets d'habillement. Cependant l'un des volontaires $[\ldots]$ me montre ses pieds nus. J'exige que ses ex-chefs lui rendent ses chaussures. Satisfaction ne m'est donnée qu'à moitié, car on le munit de savates éculées inutilisables.

C'est alors que survient l'incident qui va provoquer par la suite l'expulsion de Fostikov de Lemnos ; plusieurs officiers se précipitent sur des partants pour les dépouiller de leurs capotes ou chaussures neuves :

Je donnai l'ordre aux gendarmes d'arrêter un individu dont la violence [...] était flagrante, ce qu'ils firent bien que l'homme encouragé par ses chefs et même par le général Fostikoff se débattit furieusement ; [...] Fostikoff commanda alors aux gradés qui assistaient à cette scène de l'arracher des mains des gendarmes. L'ordre fut naturellement exécuté avec empressement et les gendarmes durent lâcher leur prisonnier. ${ }^{113}$

Il ressort de ces rapports que peu d'hommes se sont portés volontaires lors de ces tournées dans les camps. Alors comment peut-on expliquer que les navires aient été remplis par près de 6000 volontaires ? La réponse nous est fournie par le général Broussaud :

À vrai dire, un assez petit nombre de Cosaques se sont détachés du rang à l'appel de l'officier français, mais un beaucoup plus grand nombre ont rallié furtivement les détachements en marche vers l'embarcadère, profitant du moment où la surveillance brutale des officiers se relâchait. ${ }^{114}$

Dans le camp du Don, la visite se déroule de manière bien plus calme, mais avec là aussi son lot d'incidents (volontaires dépouillés, officiers tournant le dos pendant qu'on leur parle, etc.). Une fois à bord du Rechid Pacha, l'atmosphère se détend. Un officier de Broussaud monte faire un dernier discours aux 3300 réfugiés qui s'y trouvent, avant de rédiger son rapport :

J'invitai aussitôt les volontaires pour la Sovdépie à se grouper [...], ce que les hommes firent aussitôt de très bonne grâce. Je montai sur le pont supérieur d'où je pouvais dominer la foule [...] Un simple geste de la main me suffit pour obtenir le silence. Je commençai par leur dire que [...] le général Broussaud [...]

112. Ibid., rapport du capitaine Michelet, 11 avril 1921

113. SHMT, 56 C 61-62, rapport du capitaine Michelet, 27 mars 1921.

114. SHAT, 20 N 1155, lettre 198/S du général Broussaud au général commandant le COC, 12 avril 1921. 
m'a chargé de leur apporter tous ses meilleurs souhaits de bon voyage [...] et d'un accueil favorable dans leur patrie. [...] Je fus interrompu par les remerciements chaleureux et les hourras de tous ces hommes. Je levai la main, le silence se rétablit aussitôt. [...] Un des hommes me pria de lui accorder la parole, je me gardai bien de la lui refuser. Il me pria au nom de tous ses camarades de remercier le commandement français [...] et en particulier le général Broussaud de les avoir hébergés et soignés et de leur avoir donné la possibilité de s'affranchir des mauvais traitements que leur faisaient subir ici leurs officiers. ${ }^{115}$

À 12 h 30 , le 27 mars, le Rechid Pacha appareille. Les embarquements continuent ensuite sur le Don, qui appareille à son tour le 31 mars au matin, chargé de 3188 volontaires. Avant le départ, le même officier est monté faire le même discours : «La scène du Rechid Pacha se reproduisit. Peut-être un peu moins d'enthousiasme, mais mes paroles furent très bien accueillies, également par des hourras »116. Arrivés à Odessa, les Cosaques sont accueillis selon le service de renseignements français avec une fanfare jouant $L$ 'Internationale et des discours :

Les soldats ont été reçus très amicalement par les Rouges. Formés en détachement, on les a conduits aussitôt dans des casernements où un repas leur fut servi. Les officiers qui se trouvaient parmi les réfugiés ont été reçus beaucoup plus froidement; on les a remis dans un détachement à part. Toutefois, aucun mauvais traitement à l'égard des officiers n'est à signaler. ${ }^{117}$

Les autorités soviétiques proclament même que les réfugiés encore à Constantinople sont les bienvenus : «La majorité est formée de Cosaques, de paysans mobilisés, de petits employés. À tous ceux-ci le retour en Russie n'est pas interdit, ils peuvent venir, ils seront pardonnés ${ }^{118}$. Mais en même temps, ces autorités font savoir qu'un nouveau rapatriement ne pourra se faire qu'après une entente au niveau gouvernemental, ce qui est hors de question pour les Français. Le débouché russe semble se fermer.

Ainsi, plus de 6000 Cosaques sont retournés en quelques jours en Russie. Wrangel ne peut laisser passer l'outrage : dans un communiqué officiel et une lettre adressée aux maréchaux français, il crie à la trahison. Il écrit aussi au haut-commissaire français à Constantinople, pour dénoncer l'attitude de Broussaud : « [...] Les autorités de Lemnos ont apparemment dépassé dans leur zèle au service toutes les limites et ont abusé ma confiance de soldat [...] ». Il l'accuse pêle-mêle d'avoir fait de la propagande pour discréditer les officiers russes, de les avoir injuriés et humiliés par le déploiement de la force armée, d'avoir fait embarquer par la ruse des Cosaques indécis, puis de leur avoir interdit de redescendre du navire. Selon lui, des hommes désespérés se seraient jetés à la mer pour ne pas être rapatriés de force.

115. Ibid., rapport du sous-lieutenant Schmitt, 29 mars 1921.

116. Ibid.

117. Ibid., $20 \mathrm{~N} 1097$, compte rendu de renseignements $131 \mathrm{du}$ service de renseignements de Constantinople, 13 avril 1921.

118. Ibid., $20 \mathrm{~N}$ 1154, radio de Moscou, 5 avril 1921. 
Wrangel a envoyé copie de cette lettre à Broussaud dans laquelle on lit en marge des annotations de la main du destinataire : trois fois « faux », trois fois « inexact» ... quant à l'épisode de l'évasion à la nage, il est annoté : « faux et ridicule »119. Le haut-commissaire des États-Unis reçoit quant à lui une lettre accusant Broussaud d'avoir fait embarquer 3000 Cosaques contre leur gré à la pointe des baïonnettes L'histoire des Cosaques embarqués de force pour être livrés aux Soviets est largement reprise dans la presse russe blanche : La Cause commune à Paris, Rus' et Novoe Vremja à Belgrade ; on y dépeint des scènes déchirantes : Cosaques pleurant en passant à Constantinople devant le yacht de Wrangel, trois officiers livrés aux Rouges par Broussaud pour être sortis du camp de Lemnos sans autorisation ${ }^{120}$. Le bras droit de Wrangel, le général Šatilov, se charge de diffuser cette rumeur lors d'un voyage en Serbie. L'affaire met évidemment en émoi la communauté russe en exil.

Face à cette campagne, Broussaud réagit. Il écrit au général Abramov, qui vient de remplacer Fostikov :

Si quelques hommes ont gagné la côte à la nage, on doit les connaître. Où sontils et qui sont-ils ? Il serait très intéressant de savoir s'ils ont réellement demandé à qui que ce soit l'autorisation de débarquer. Je vous prie donc de vouloir bien les faire rechercher et me les envoyer. Ils seront interrogés en présence d'un officier russe que vous désignerez. Vous me connaissez assez pour savoir que s'ils disent la vérité, ils ne seront nullement inquiétés. Dans le cas contraire, vous serez d'avis, comme moi, que leur imposture doit être punie et la vérité rétablie. ${ }^{121}$

Une semaine plus tard parvient la réponse embarrassée du chef d'état-major d'Abramov. Elle évoque à nouveau la rumeur selon laquelle un homme se serait jeté à la mer, mais on ne peut le retrouver car il se serait noyé, il était donc impossible d'établir la preuve du fait colporté..., d'autant que celui-ci est à présent lointain ${ }^{122}$. Quant à Wrangel, il reçoit une courte lettre très digne de Broussaud, accompagnée de la décoration qu'il lui avait remise suite à l'évacuation de la Crimée.

\section{Autres destinations}

L'autre destination proposée par les Français est le Brésil. En effet, l'État de São Paulo s'est déclaré prêt à recevoir 10000 agriculteurs pour les plantations de café. Fin février, 250 candidats seulement se sont fait connaître. Cette réception peu enthousiaste est en partie liée à l'attitude de l'état-major russe, qui a fait courir le bruit que la Serbie allait accepter bientôt de recevoir des troupes russes, et qui a

119. Ibid., 20 N 1155, lettre 5949 du général Wrangel au général Pellé, 2 avril 1921.

120. Article de Novoe Vremja du 26 avril 1921.

121. SHAT, 20 N 1158, lettre 211/S du général Broussaud au général Abramov, 5 mai 1921.

122. Ibid., lettre 465 du colonel Nikolskij au général Broussaud, 11 mai 1921. 
décrit le Brésil comme une terre d'épouvante, infestée de maladies tropicales, où les Russes seraient traités comme des esclaves sous le fouet des planteurs ${ }^{123}$.

Finalement, ce sont 1029 Cosaques qui se présentent au quai le 29 avril, lorsque le paquebot Rion vient les embarquer ${ }^{124}$.

Au lendemain de la Grande Guerre, l'idée d'intégrer des soldats slaves à la Légion étrangère apparaît comme une excellente occasion de rééquilibrer un corps qui, selon Aristide Briand, comporte trop d'éléments germaniques ${ }^{125}$. Le Cosaque Svidin est d'une autre opinion : « La France avait sur le dos la guerre au Maroc, et ça l'arrangeait bien de récupérer ces magnifiques soldats que sont les Cosaques » ${ }^{126}$.

Quel que soit le grade des volontaires, les engagements se font comme soldats de $2^{\mathrm{e}}$ classe. Nous n'avons trouvé trace que de 470 engagés de Lemnos dans les archives militaires.

\section{L'ouverture des pays slaves}

Depuis décembre 1920, la porte serbe est fermée malgré les nombreuses requêtes des autorités françaises et de Wrangel. Faute de moyens logistiques, les Serbes ont en effet eu le plus grand mal à accueillir les 20000 réfugiés qu'ils avaient acceptés aux premiers jours de l'évacuation.

Au début du mois d'avril, Wrangel annonce pourtant aux autorités françaises que le prince régent serbe souhaite utiliser une partie de l'armée russe pour des travaux d'État (gardes-frontière, construction de voies ferrées, d'une route entre Nis et Mitrovitza). Peu après, il affirme que par suite d'une visite de son chef d'étatmajor Šatilov, la Bulgarie serait prête à recevoir 7000 hommes.

Les autorités militaires françaises restent cependant sceptiques : Wrangel a déjà fait par le passé pareilles déclarations non suivies d'effet. Elles soupçonnent qu'il ne s'agit là que d'une très hypothétique possibilité destinée à saboter les départs vers la Russie ou le Brésil. Ces informations sont reçues avec d'autant plus de suspicion qu'elles proviennent toutes de Šatilov, qui a violemment critiqué la France dans la presse pendant sa tournée dans les Balkans. D'autre part, Wrangel insiste sur le fait que les premiers contingents à partir devront être, selon un accord passé entre Šatilov et le Gouvernement serbe, des Cosaques de Lemnos, notamment le régiment technique du Kuban’. Or, les Français préféreraient voir partir les

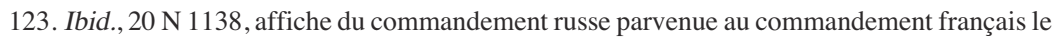
7 mars 1921 .

124. La plupart n’y arriveront jamais : cf. Bruno Bagni, «Les Russes en Corse », Études corses, 49, 1999, p 123-167. Paul Robinson, pour étayer sa thèse selon laquelle le moral à Gallipoli était bien meilleur qu'à Lemnos, affirme que la plupart de ceux qui ont accepté de partir au Brésil étaient des Cosaques. En fait le Rion a embarqué 1029 Cosaques à Lemnos, et 1913 soldats à Gallipoli.

125. ADQO, Europe 1918-1940, URSS 259, lettre 160 du président du Conseil au ministre de la Guerre, 24 janvier 1921.

126. Svidine, Le secret de Nicolas Svidine, p. 119. 
troupes régulières stationnées à Gallipoli qui, pour avoir été plus compromises dans la guerre civile, sont moins enclines à retourner en Russie. Désabusé, Charpy constate : «Continuant leur tactique, Russes veulent se débarrasser Cosaques et conserver intacte leur armée de Gallipoli »127.

Le 28 avril arrive finalement la confirmation officielle : l'attaché militaire français à Belgrade annonce que le Gouvernement serbe accepte de recevoir 5000 réfugiés comme travailleurs ${ }^{128}$. La nouvelle se répand comme une traînée de poudre sur l'île : les chefs russes lancent un ordre général d'embarquement pour la $1^{\text {re }}$ division du Kuban' ; les hôpitaux sont vidés des malades qui ne veulent pas être de reste... La suite est racontée par le commandant du stationnaire :

l'événement promis pour la semaine de Pâques, attendu depuis chaque jour pour le lendemain, ne s'étant pas produit et paraissant ne pas devoir se produire de sitôt, il en résulte un état général de fièvre et de nervosité mêlé de découragement. La manifestation en est visible dans l'arrêt presque complet des travaux : on ne s'installe plus. ${ }^{129}$

En fait, ce n'est pas vers la Serbie que va se faire le premier grand départ pour les Balkans mais vers la Bulgarie.

\section{Les départs pour la Bulgarie}

Début mai, le Gouvernement bulgare fait savoir à l'ambassadeur de France à Sofia qu'il accepte de recevoir immédiatement 2000 hommes qu'il emploiera comme agriculteurs, exploitants forestiers et ouvriers en usines ou sur des chantiers de chemin de fer. Wrangel demande alors que ce placement ne concerne que des Cosaques de Lemnos, ce à quoi Charpy s'oppose et décide de prendre 1000 hommes à Lemnos et 1000 à Gallipoli. Le 23 mai, le Kherson se présente à Lemnos après avoir embarqué un millier de soldats à Gallipoli. 1030 Cosaques du Don, 6 généraux, accompagnés de 53 femmes et 14 enfants sont embarqués dans le plus grand calme. « Ce départ est le premier que le commandement russe local ait consenti à organiser et diriger personnellement», commente le commandant du stationnaire ${ }^{130}$. Et pour cause ! C'est le premier qui réponde à ses projets...

Mais cet état de grâce ne dure guère. Lorsque le navire accoste à Burgas, en Bulgarie, les autorités bulgares s'opposent au débarquement. Un colonel monte à bord et montre un message de l'état-major bulgare disant en substance qu'il paraîtrait

127. SHAT, 20 N 1155, note en marge sur lettre 6257 du général Šatilov au général Charpy, 2 mai 1921.

128. Ibid., 20 N 1141, télégramme 82/3R du colonel Despres à Guerre, Paris, 28 avril 1921.

129. SHMT, 57 C 27, journal n 62 du lieutenant de vaisseau Le Luc, commandant de 1'Agile, 10 mai 1921.

130. Ibid., journal $n^{\circ} 73$ du lieutenant de vaisseau Le Luc, commandant de l'Agile, 24 mai 1921. 
que les hommes embarqués à Gallipoli sont « des révoltés qui auraient quitté le camp de Gallipoli sans l'autorisation de leurs chefs. Dans ces conditions nous ne pouvons les accepter sur notre territoire vu que nous avons demandé des travailleurs et des gens soumis $»^{131}$. Finalement, après une longue journée de tractations, les Bulgares acceptent de laisser descendre tous les passagers. En fait, si à Lemnos les Russes ont pu faire embarquer deux régiments encadrés par leurs officiers, cela ne fut pas le cas à Gallipoli où une partie des embarqués fut prise parmi les démobilisés, à la grande fureur du commandant russe local, le général Kutepov ${ }^{132}$. Suite à cet incident, le Gouvernement français réagit promptement à l'encontre de Charpy et du hautcommissaire :

Il me revient qu'un obstacle à l'écoulement des réfugiés russes sur la Bulgarie et la Serbie serait élevé par les autorités militaires françaises qui feraient des difficultés à laisser partir les réfugiés de Lemnos avant ceux de Gallipoli. Je vous rappelle que notre première préoccupation doit être de nous débarrasser des réfugiés, et que cette considération doit primer toutes les autres ${ }^{133}$.

Cette fois-ci, Wrangel semble avoir gagné : c'est son état-major qui décidera désormais qui doit partir en priorité.

Le 25 juin, un nouveau départ a lieu à destination de la Bulgarie, organisé non pas par les autorités russes mais par l'Union agricole des Cosaques : le Samara embarque 1089 Cosaques, pour la plupart du Don. Mais les deux représentants de l'Union des Cosaques qui devaient choisir les partants arrivent deux jours après le départ du bateau et sont furieux. Ils voulaient des Koubanais, non des Cosaques du Don ! Le chef d'escadron Brun, qui a remplacé Broussaud, se justifie : «Personne ne m'avait prévenu de ce détail, et d'ailleurs il n'y avait pas 1000 Koubanais ici ${ }^{134}$. En fait, profitant de l'absence des délégués de l'Union, les chefs russes ont fait embarquer des unités militaires constituées menées par deux généraux. Ils ne vont cependant guère loin : arrivés à Constantinople, ces réfugiés sont aussitôt renvoyés à Lemnos par les autorités françaises, peu soucieuses de se heurter à nouveau à un refus des autorités bulgares. Ce retour contrarie à son tour le général Abramov. Refusant de donner ordre à ses troupes de débarquer, il s'efforce d'organiser une mutinerie à bord par divers moyens. Peine perdue. Selon le rapport de Brun : « Les essais de communication de la terre au bateau (barque, nageurs, portevoix...) ayant été interceptés, la résistance à bord, ne se sachant pas soutenue n'a

131. SHMV, 1BB7 249, rapport de l'aspirant Brezellec, 31 mai 1921.

132. Aleksandr P. Kutepov, qui fut quelques années plus tard enlevé en plein Paris par les services secrets soviétiques, et sans doute exécuté.

133. ADQO, Europe 1918-1940, URSS 264, télégramme 1148 de Peretti de la Rocca à HC Constantinople, 8 juin 1921.

134. SHAT, 20 N 1158, lettre 2139 du chef d'escadron Brun au général commandant le COC, 28 juin 1921. 
pas été sérieuse ${ }^{135}$. Les deux délégués de l'Union peuvent alors choisir les partants dans une atmosphère tendue :

Les inscriptions pour le départ se sont faites au camp français, ce qui a rendu inutiles les précautions russes (défense de s'inscrire, menaces, arrestations, essai de d'encerclement des camps par des sentinelles, etc.), l'affluence était telle que le commandement russe a senti vite son impuissance. L'influence du général Abramoff sur sa troupe se trouve très amoindrie et je ne serais pas étonné qu'après une autre tentative de ce genre, il se retire ; nos rapports deviennent naturellement un peu tendus. ${ }^{136}$

Le 10 juillet, le Rechid Pacha embarque cette fois 904 réfugiés répondant aux souhaits de l'Union. Au port de Varna, les Français doivent à nouveau faire de multiples démarches auprès du Gouvernement bulgare très réticent à les laisser débarquer, suite à une nouvelle intervention de Wrangel, furieux que cette évacuation se soit effectuée sans son autorisation ${ }^{137}$. Les réfugiés débarquent enfin le 18 juillet.

Les derniers départs pour la Bulgarie ont lieu fin août-début septembre 1921. Cette fois-ci, ce sont les autorités russes qui ont désigné les partants : 1186 Cosaques s'embarquent pour Bourgas le 27 août, puis 1200 autres deux jours plus tard. Au début du mois de septembre, le Samara embarque 1300 Cosaques. Peu de temps après, 3500 Cosaques en unités militaires partent en Bulgarie sans que l'on sache dans quelles conditions, les archives étant muettes sur le sujet.

\section{Les départs pour la Serbie}

Avec la Bulgarie, la Serbie est l'autre destination dont rêvent les autorités russes et une grande partie des réfugiés. Aussi, lorsque début mai l'évêque Benjamin, exévêque de Sevastopol', vient faire à Lemnos une visite pastorale pour la Pâque orthodoxe, il se charge dans ses discours de faire de la propagande pour le départ en Serbie, ce que ne peut faire Wrangel, persona non grata sur l'île.

Un des principaux obstacles aux transferts massifs de réfugiés vers la Serbie était l'engorgement du port de Kotor. Le 11 mai l'obstacle est levé. Le Gouvernement grec donne son accord pour que les réfugiés soient débarqués à Salonique, puis transférés en train jusqu'à la frontière yougoslave. Au poste frontière de Guevgueli les attend un poste sanitaire mis en place par le ministère yougoslave des Travaux publics avec bains, désinfection et buffet. Suivant les instructions du Gouvernement, afin de ne pas renouveler la cuisante expérience du premier transport en Bulgarie, les autorités militaires françaises laissent Wrangel gérer les départs des 5000 hommes acceptés par les Serbes. Priorité est donc donnée à Lemnos.

135. Ibid., lettre 230/S du chef d'escadron Brun, 10 juillet 1921.

136. Ibid

137. Bernachot, Les armées françaises en Orient, p. 109. 
Le premier bateau à venir chercher des réfugiés pour cette terre promise est le Rechid Pacha. Le 30 mai, il embarque à Lemnos 2634 Koubanais (deux régiments, plus le régiment technique, encadrés par deux généraux) accompagnés de 136 femmes et 27 enfants qu'il va débarquer à Salonique. Le 3 juin, le Kherson vient chercher un second contingent de 2000 Cosaques pour Kotor. Ce sera le dernier ${ }^{138}$.

\section{Dernier départ pour le Caucase}

Depuis le mois d'avril, les retours en Russie sont bloqués. Les Soviets exigent des négociations au niveau gouvernemental, au grand dam des Français. D'après le service de renseignements français en effet, $60 \%$ des Cosaques du Don seraient favorables au rapatriement ${ }^{139}$. Une proposition surprise vient relancer cette possibilité. Le 9 mai, un certain Serebrowski, président du Comité des naphtes [pétrole] de Baku, en Azerbaïdjan, propose d'embaucher 6240 ouvriers parmi les réfugiés. Il garantit qu'à l'exception des officiers, aucunes représailles n'auront lieu à leur encontre, et qu'à la fin de la saison d'été, ils pourront retourner dans leurs foyers ${ }^{140}$. Le 13 mai, un premier contingent de volontaires des camps de Constantinople est envoyé à Batum, en Géorgie, pour rejoindre Baku. Le 14 juin le Rechid Pacha vient chercher les volontaires de Lemnos pour un second voyage: il embarque 2180 réfugiés, dont une cinquantaine de femmes et enfants. Les Koubanais laissent pour Broussaud une lettre de remerciement :

En quittant aujourd'hui l'île de Lemnos pour une existence et une situation tout à fait différentes, et dont les conditions nous sont encore inconnues, nous adressons notre cordial remerciement à son Excellence le général Broussaud pour les soins attentifs, humains et charitables, qu'il a eus pour nous pendant notre séjour à Lemnos. Durant un séjour dans l'île de plus d'une demi-année nous avons pu constater, en toute occasion, l'intérêt vigilant que nous ont témoigné les représentants de ces nobles nations : la France et l'Amérique. On nous a nourris, habillés et, par-dessus tout, on a sauvegardé notre liberté et notre indépendance contre les attentats dirigés contre elles de quelque côté que ce fût. Nous, qui avons autrefois combattu dans l'alliance franco-anglaise pour la défense de nos intérêts communs, et qu'un destin implacable a jetés dans cette île, nous exprimons nos regrets quant à l'offense imméritée infligée à la noble France, au lieu et place de la reconnaissance due, pour le soi-disant envoi forcé, par l'autorité française, de nos frères Cosaques en Russie Soviétique, ce qui, en réalité, n'a pas eu lieu et n'est qu'une infâme calomnie. Gloire, honneur et, de notre part, reconnaissance profonde aux nobles peuples français et américain, pour l'hospitalité qu'ils nous ont offerte. Le souvenir en restera gravé dans nos cœurs pour de longues années et nous tâcherons de le leur revaloir, si le destin le permet, une fois rendus dans

138. Selon Paul Robinson, 1000 Cosaques supplémentaires seraient partis en Tchécoslovaquie.

139. SHAT, 20 N 1158, bulletin de renseignements 212/S du capitaine Michelet, 10 mai 1921.

140. SHMT, 56 C 61-62, lettre 4781 de Serebrowski au commandement français à Constantinople, 9 mai 1921. 
nos pays. (De la part des Cosaques du Kuban’ partant de Lemnos pour les travaux de Bakou le 13 juin 1921). ${ }^{141}$

Lors d'une escale à Constantinople, les Français laissent monter à bord des représentants de Serebrowski, dont un certain Isakin, délégué des unions professionnelles de Baku, qui fait aux passagers un discours retranscrit dans un rapport du service de renseignements :

M. Issakine a salué les partants au nom du prolétariat ouvrier de Bakou, leur disant qu'il les invite à partir non pas dans un paradis terrestre, mais dans un pays où les conditions économiques sont dures et pénibles. Mais ce pays est leur patrie et ils peuvent être sûrs d'y être reçus en frères et d'être traités sur le même pied que tous les autres. Leur participation souvent inconsciente à la lutte contre la Russie soviétiste leur est pardonnée et sera oubliée. Les hommes ont répondu par un hourrah unanime à son discours. Je me suis adressé ensuite aux hommes, leur disant que tous ceux qui estiment les garanties offertes [...] insuffisantes et qui ne veulent pas partir en Russie sont libres de descendre immédiatement à terre. [...] Aucun homme ne s'est présenté pour être débarqué. ${ }^{142}$

Le débarquement à Batum se fait sans problème.

Les deux voyages n'ayant pas permis d'évacuer la totalité des volontaires demandés par Serebrowski, un nouveau transport de 1000 Cosaques est prévu pour juillet. C'est un échec total. Le navire arrive dans le port de Moudros le 20 juillet au soir : il faut donc attendre le lendemain pour commencer les opérations d'embarquement. Aussi les chefs russes ont-ils toute la nuit pour organiser la résistance. La suite est racontée par Brun :

Tous les incidents possibles étaient créés au moment de la décision des volontaires (un officier de l'école Alexeieff [...] a même insulté [...] un officier français. Aussitôt arrêté et conduit au camp, une compagnie armée de l'école est venue pour essayer de le délivrer. Elle s'est toutefois retirée [...]). L'autre école a sifflé au passage des Français. [...] Tous les chemins d'accès, pistes, sentiers étaient gardés par des officiers sans autre arme apparente que des bâtons, mais suffisamment pour terroriser les partants. ${ }^{143}$

Dans une lettre postérieure, Abramov dit regretter «profondément » les incidents, mais en attribue la responsabilité à l'officier français chargé de faire la tournée des camps ; il explique ensuite l'affaire de la tentative de libération d'un officier de l'école par le bruit qui aurait couru selon lequel il allait être embarqué de force pour Batum, et ajoute que du reste, les élèves étaient sortis avec « des fusils sans culasses et sans cartouches ${ }^{144}$. Le navire appareille après avoir embarqué... sept Cosaques qui ont réussi à passer. Brun tire les conclusions de ce fiasco : « Je pense qu'après

141. Bernachot, Les armées françaises en Orient, p. 382.

142. SHAT, 20 N 1158, rapport du lieutenant Delimarskij, 19 juin 1921.

143. Ibid., lettre 2226 du commandant d'armes Lemnos au COC, 21 juillet 1921.

144. Ibid., 20 N 1155, lettre 1337 du général Abramov au commandant Brun, 24 juillet 1921. 
cette expérience il est inutile d'essayer désormais des départs en masse. La proportion en officiers ou élèves est trop forte pour me permettre d'agir sur les simples Cosaques comme autrefois ${ }^{145}$.

En effet, il n'y aura plus de départs pour la Russie. Au total, en additionnant les départs pour Novorossijsk, Odessa et Batum, ce sont 9233 Cosaques qui sont rentrés en Russie à partir de Lemnos (dont les 1100 venus de Tchataldja).

\section{Les départs pour la Grèce}

Vers le mois d'avril 1921, une nouvelle occasion de placer des réfugiés se présente. La Grèce vient de mobiliser et d'entrer en guerre contre les troupes de Mustafa Kemal. Le manque de bras se fait ressentir dans les campagnes et les industries. Les employeurs helléniques commencent à s'intéresser à ce vivier de travailleurs potentiels, des orthodoxes, concentrés sur une île grecque. Broussaud note que « les gens du Don acceptent cette solution avec enthousiasme »; jamais à cours d'une amabilité sur le corps du Kuban', il ajoute : «Il n'en paraît pas être de même des Koubanais qui tiennent, avant tout, à ne rien faire ${ }^{146}$.

En avril un entrepreneur grec de Lesbos propose d'embaucher 3000 Cosaques. Wrangel approuve, qui prévoit d'y envoyer des éléments « sûrs » encadrés par des officiers, en particulier les élèves des écoles. Commentaire de Charpy : « De telles prétentions [...] ne sauraient même être discutées $»^{147}$. Il n'y aura pas de suites immédiates, à cause de réticences de la part des autorités grecques.

La situation se débloque enfin début juin : La Grèce accepte les réfugiés qui souhaitent travailler, sans limitation de nombre, mais à titre d'isolés. Selon Broussaud, cette décision n'est pas due qu'à des considérations économiques ; elle serait liée à l'ouverture de la Serbie et de la Bulgarie : «Il est évident que les Grecs redoutent de laisser partir trop de Russes, en âge de porter les armes, vers les autres pays balkaniques ${ }^{148}$.

Immédiatement l'affiche suivante est placardée dans les camps :

Le sous-préfet de Kastro m'a fait savoir que le gouvernement grec admettait la circulation libre des réfugiés russes dans tout le royaume, pour y trouver du travail. Le manque de bras est général dans toute la Grèce, surtout aux approches de la moisson et en prévision de la cueillette des fruits et des vendanges. On demande des agriculteurs dans toute l'Attique et la Thessalie, à Larissa, Triyala, Karditsa, Thèbes, etc. ; des agriculteurs et des viticulteurs dans le Péloponnèse, des boulangers au Pirée. [...] Les moyens de se rendre en Grèce sont les suivants : bateau à vapeur le dimanche. [...] Je délivrerai [...] 4 jours de vivres à

145. Ibid., $20 \mathrm{~N}$ 1158, lettre 2226 du commandant d'armes Lemnos au COC, 21 juillet 1921.

146. Ibid., lettre 1635 du général Broussaud au général commandant le COC, 12 avril 1921.

147. SHMT, 56 C 61-62, lettre 100 du général Charpy au général Broussaud, 30 avril 1921.

148. SHAT, 20 N 1158, lettre 224/S du général Broussaud au général commandant le COC, 8 juin 1921. 
chaque émigrant. Les départs peuvent avoir lieu à raison de 3 à 400 personnes par paquebot $[\ldots] \cdot{ }^{149}$

Broussaud a reçu l'autorisation de payer le voyage aux indigents. 130 réfugiés sautent immédiatement sur l'occasion et partent par le premier bateau. Le dimanche suivant, ce sont 435 Cosaques qui partent.

Cette proposition n'est pas du goût des autorités russes. Le service de renseignements de Lemnos note qu' « une propagande effrénée est faite contre les départs en Grèce ». Selon lui, les candidats au départ doivent « cacher leur dessein jusqu'au jour du départ et se glisser dans la nuit avec leurs bagages jusqu'à l'état-major français. Faute de prendre ces précautions, ils risquent d'être arrêtés par leurs officiers et dépouillés de leurs vêtements et linge de rechange ${ }^{150}$. Beaucoup hésitent pour d'autres raisons : «Ce qui arrête les Cosaques, c'est la crainte d'être absolument sans ressources dans un pays dont ils ne connaissent pas la langue et où personne ne s'occupe d'eux »151. Afin de mieux convaincre les hésitants, Brun obtient l'autorisation de leur payer systématiquement le billet de bateau, leur donner des chaussures et du linge neufs, d'offrir enfin une prime de 50 drachmes. Il fait aussi afficher des lettres écrites par des Cosaques établis en Grèce et qui s'y trouvent bien. Afin de contrebalancer l'effet produit, l'état-major d'Abramov fait afficher une sorte de mode d'emploi de ces lettres assez surréaliste :

La plupart des lettres à cause de la crainte de censure sont embrouillées, peu claires, et pour connaître la vérité sur la Grèce il faut lire entre les lignes. [...] Plus la vie est représentée comme bonne, plus la réalité est mauvaise. Les lettres [...] ne sont en effet que des lettres chiffrées, étant donné que ceux qui écrivent [...] se sont entendus avec les restants pour que toute appréciation positive soit considérée comme négative et que plus cette appréciation est enthousiaste, pire est la réalité. 152

Ainsi ces départs individuels vont continuer chaque semaine jusqu'à la fermeture du camp :

\begin{tabular}{|c|c|c|c|c|c|c|c|c|}
\hline Date & 26 juin & 3 juillet & 9 juillet & 15 juillet & 18 juillet & 22 juillet & 7 août & 14 août \\
\hline partants & 372 & 150 & 275 & 277 & 140 & 68 & 39 & 35 \\
\hline
\end{tabular}

On ne sait si ces chiffres sont exhaustifs ou s'il y a des lacunes dans les archives. On observe aussi quelques départs groupés : ainsi le 26 juin un sujet britannique vient recruter 211 travailleurs qu'il transporte ensuite à Cassandra, sur la côte de Chalcidique ; le 16 août, c'est un entrepreneur grec qui embarque 1260 Cosaques

149. Ibid., ordre 70 du général Broussaud, 1 er juin 1921.

150. Ibid., rapport 228/S du service de renseignements Lemnos, 6 juillet 1921 .

151. Ibid., lettre 2139 du commandant Brun au général commandant le COC, 28 juin 1921.

152. Ibid., rapport 228/S du service de renseignements Lemnos, 8 août 1921. 
pour Kalamata. Au total, selon Paul Robinson, quelque 2500 Cosaques sont répartis en Grèce ${ }^{153}$.

\section{Les évasions}

Certains ont quitté Lemnos clandestinement. Le moyen classique est de voler ou d'acheter une barque à des insulaires ou bien de payer un passeur. Nikolaj Svidin quant à lui parvient, grâce à la complicité de l'officier chargé du contrôle, à s'embarquer clandestinement vers Kotor sur le Kherson ${ }^{154}$. Leur nombre exact est impossible à estimer, car les renseignements fournis par les archives sont extrêmement minces. Dès décembre, un informateur du service de renseignements affirme que «le nombre des officiers et soldats qui s'échappent de Moudros [...] s'accroît de jour en jour. [...] Ils viennent en quête d'emplois à Constantinople ». Selon lui, certains deviendraient des mercenaires au sein des armées kémalistes; il donne même les soldes offertes : 200 à 300 livres pour les officiers, 90 à 120 livres pour les hommes de troupes ${ }^{155}$. La crainte de voir les Russes participer à la guerre en Anatolie est récurrente, mais rien ne permet d'affirmer qu'un nombre conséquent de réfugiés s'en soit mêlé. Il semblerait, toujours selon le service de renseignements français, qu'une part importante de ces évadés soit passée en Bulgarie : « 2000 Cosaques [...] ont quitté Constantinople-Lemnos sans autorisation ni passeports, pour aller rejoindre un autre groupe de 2000 fugitifs déjà installés à Sofia »156.

\section{La fermeture des camps}

Ainsi se vident peu à peu les camps de Lemnos. Après le pic de 21000 réfugiés de février à avril 1921, les effectifs fondent : 17000 en mai, 12000 en juin, 7000 en juillet, 4000 en août. Rapidement, il n'apparaît plus nécessaire de garder plusieurs camps. Début juin, Broussaud commence à concentrer les Cosaques du Don restants au camp de Moudros-Ouest, à Kaloyeraki, mieux approvisionné en eau. Le 25 juin est fermé le camp du Don de Moudros-Est. Dans le même temps, Broussaud demande à ses autorités si sa présence est toujours nécessaire face à un effectif réduit, soulignant que le commandant Brun pourrait parfaitement assurer le même service $^{157}$. La passation de pouvoir est rapide : le 20 juin, le général Broussaud

153. Robinson, The White Army in Exile, p. 42.

154. Svidine, Le secret de Nicolas Svidine, p. 120 -125.

155. SHAT, 7 N 3211, compte rendu de renseignements 28 du service de renseignements de Constantinople, $1^{\text {er }}$ décembre 1920.

156. Ibid., $20 \mathrm{~N}$ 1097, compte rendu de renseignements $111 \mathrm{du}$ service de renseignements de Constantinople, 10 mars 1921.

157. Ibid., 20 N 1158, lettre 224/S du général Broussaud au général commandant le COC, 8 juin 1921. 
abandonne son commandement et quitte Lemnos. À la fin du mois de juin, c'est l'utilité même du camp de Moudros qui est mise en cause par le commandant du stationnaire, qui s'interroge sur son coût :

Les frais généraux de cette installation n'ont pas diminué d'une manière sensible. Ces frais généraux (mission militaire, compagnie de tirailleurs, stationnaire, éclairage électrique des camps à l'essence, eau potable, batelage, salaire des auxiliaires, location des terrains, etc.) ne semblent plus en proportion avec le nombre de réfugiés russes existants. ${ }^{158}$

Le 9 septembre, il ne reste plus que 600 réfugiés sur l'île, dont une centaine de malades dans un état grave. Brun fait afficher l'ordre suivant :

1 - Le camp de Lemnos est supprimé. 2 - Les malades graves seront transportés à Constantinople avec le personnel médical. 3 - Le reste doit partir en Grèce ou à Batoum. 4 - Ceux qui n'auront pu ou voulu partir seront conduits à Gallipoli. ${ }^{159}$

Le 16 octobre 1921, c'est le départ des derniers malades vers les hôpitaux de Constantinople. Le camp de Lemnos ferme définitivement.

\section{Conclusion}

Ainsi se termine l'histoire des Cosaques sur l'île de Lemnos, du moins telle que l'on peut la reconstituer d'après les archives militaires françaises. Sur cet épisode - resté largement méconnu de l'histoire de l'après-guerre, si ce n'est de celle de l'émigration russe et qui a jusqu'à présent été essentiellement retracé à partir des archives de l'état-major russe - les sources françaises projettent un nouvel éclairage. Elles confirment l'acuité des antagonismes entre les deux principaux protagonistes. Les autorités militaires françaises sont avant tout préoccupées de la dispersion - également conçue comme moyen d'un démantèlement en douceur - des armées blanches par leur rapatriement en Russie et/ou leur placement sur les marchés du travail des pays limitrophes. Les autorités militaires russes poursuivent un objectif diamétralement opposé : préserver l'armée à travers son transfert collectif et organisé vers les États de la région susceptibles de l'accueillir telle quelle. Face à la volonté politique de l'état-major blanc, toujours persuadé d'une possible reconquête de la Russie, ces sources témoignent du pragmatisme qui a guidé l'action militaire française dans sa mission de soustraire au plus vite l'État français de l'assistance aux réfugiés. En présence d'objectifs aussi contradictoires, l'histoire du transit des Cosaques à Lemnos s'est manifestée sous la forme de

158. SHMT, 57 C 27, journal n 92 du lieutenant de vaisseau Le Luc, commandant de 1'Agile, 28 juin 1921

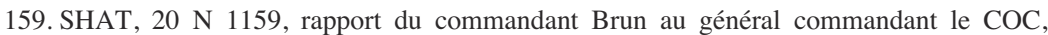
9 septembre 1921 . 
confrontations quasiment incessantes entre officiers russes et français. Ces différends n'ont sans doute pas été étrangers à la défiance de longue durée manifestée par l'état-major russe à l'égard de l'État français, alors même que nombre de réfugiés civils et en particulier les élites de l'ancienne Russie se tournaient vers la France pour y trouver asile.

Et Lemnos ? L'épisode cosaque n'est pas le dernier de son histoire... Le 28 juin 1921 il ne reste plus que 7000 Cosaques qui s'apprêtent à partir. Un gros paquebot grec, le Patris, avec à son bord 3000 réfugiés grecs évacués d'Asie mineure, chassés par les troupes de Mustafa Kemal, amarre, impromptu, sur l'île. Les autorités locales grecques n'ont pas préparé leur réception ${ }^{160}$. Un drame humain chasse l'autre.

Lycée du Coudon, La Garde (83)

histogeo@laposte.net 